\title{
STUDIES OF DESIGN PARAMETERS IN THE FABRICATION OF Nb-Al-Ge SUPERCONDUCTORS BY THE POWDER METALLURGY INFILTRATION METHOD
}

José J. Granda

M. E. thesis

December 1976

Prepared for the U. S. Energy Research and

Development Administration under Contract $W-7405-E N G-48$

\section{For Reference}

Not to be taken from this room

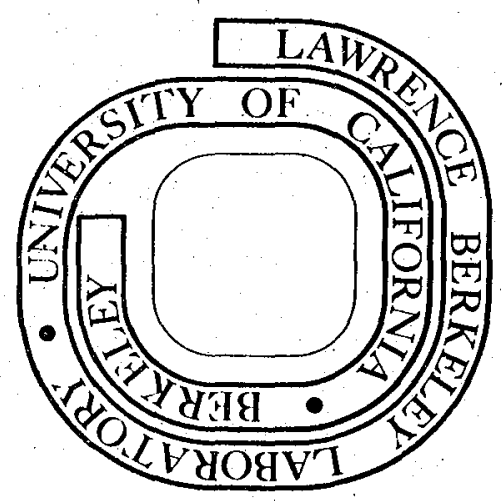


LEGAL NOTICE

This report was prepared as an account of work sponsored by the United States Government. Neither the United States nor the United States Energy Research and Development Administration, nor any of their employees, nor any of their contractors, subcontractors, or their employees, makes any warranty, express or implied, or assumes any legal liability or responsibility for the accuracy, completeness or usefulness of any information, apparatus, product or process disclosed, or represents that its use would not infringe privately owned rights. 
STUDIES OF DESIGN PARAMETERS IN THE FABRICATION OF Nb-AI-Ge SUPERCONDUCTORS BY THE POWDER METALLURGY INFILTRATION METHOD

CONTENTS

Abstract. ......................... 1 ...

I. Introduction .................... 1

II. Objectives ....................... 3

III. Experimental Methods ................. 4

A. Equipment and Materials ............. 4

B. Preparation and Characteristics of Aluminum-Germanium Eutectic。................ 4

1. Metallography: Optical, SEM ....... 4

2. Microhardness Measurements........ 6

C. Process Stages................ 7

1. Isotatic Compaction of $\mathrm{Nb}$ Powder . . ... 7

2. Sintering .............. 7

3. Infiltration with Al-Ge......... 8

4. Mechanical Deformation ......... 10

5. Diffusion Heat Treatment ........ 13

D. Determination of Superconducting Properties . .. 18

1. Critica1 Current Measurements. ...... 18

2. Transition Temperature Measurements .... 19

IV. Results and Conclusions. ............... 21

A. Processing ............... 21

B. Properties of A1-Ge Eutectic Alloy。...... 22

C. Critical Currents .............. 23

D. Critical Temperature ............. 25 
Acknowledgements ..................... 28

References ....................... 29

Tables ....................... 31

Figure Captions. . . . . . . . . . . . . . 34

Figures........................... 38 
STUDIES OF DESIGN PARAMETERS IN THE FABRICATION OF $\mathrm{Nb}-\mathrm{Al}-\mathrm{Ge}$ SUPERCONDUCTORS BY THE POWDER METALLURGY INFILTRATION METHOD

\author{
Jose J. Granda
}

Materials and Molecular Research Division, Lawrence Berkeley Laboratory and Department of Mechanical Engineering, University of California, Berkeley, California 94720

\title{
ABSTRACT
}

Experimental studies have been carried out in which the A15 phase of the $\mathrm{Nb}-\mathrm{Al}$-Ge system has been synthesized in the form of thin filaments contained in form rolled wires. A powder metallurgy approach has been used to achieve controlled porosity in compacts of sintered niobium powder. Infiltration with an aluminum-germanium eutectic alloy followed by mechanical deformation has produced sma11 interconnected filaments embedded in the $\mathrm{Nb}$ matrix. Diffusion heat treatment for a short time transforms them into the $\mathrm{A} 15$ superconducting compound with a size range of $1-5$ microns at $1300^{\circ} \mathrm{C}$ and $1-9$ microns at $1750^{\circ} \mathrm{C}$. The superconducting properties $\mathrm{T}_{\mathrm{C}}$ and $\mathrm{J}_{\mathrm{C}}$ were evaluated for samples subjected to different condition of time and temperature.

The influence of certain parameters involved in the process has been investigated. The microstructure and microhardness of the Al-Ge eutectic alloy cooled at high and low cooling rates from temperatures between $900-400^{\circ} \mathrm{C}$ have been evaluated. Optical and electron beam metallographic results are presented for the analysis of the different phases and relative compositions.

The critical temperature measured inductively is between $16.4^{\circ} \mathrm{K}$ and $18.1^{\circ} \mathrm{K}$ depending on the heat treatment. 
The critical current density as a function of the applied magnetic field is reported. These data were obtained using a pulsed magnetic field technique that measured $J_{C}$ at $4.2^{\circ} \mathrm{K}$ in fields up to $100 \mathrm{kG}$. $J_{C}$ was $8.8 \times 10^{4} \mathrm{amp} / \mathrm{cm}^{2}$ at $20 \mathrm{kG}$ and $3.6 \times 10^{4} \mathrm{amp} / \mathrm{cm}^{2}$ at $60 \mathrm{kG}$ for specimens containing approximately $20 \%$ A15 phase. 


\section{TNTRODUCTION}

Superconductivity has an important role in the generation and conservation of energy. The superconducting magnet is a critical component for high energy physics, fusion research, magnetohydrodynamics and electrical rotating machinery.

Since its discovery by Professor Heike Kamerlingh Onnes ${ }^{1}$ of the University of Leiden in 1911, the phenomenon has been a cha1lenge for physicists and engineers for fifty years. As a result of concentrated effort, however, a basic understanding and feasibility studies for applications have been accomplished in the past 25 years.

Two kinds of superconductors have achieved prominence: low field, ductile solid solutions and high field intemetallic compounds. 2 Examples of the first kind are NbTi, NbTiZr superconductors with a transition temperature of $10^{\circ} \mathrm{K}$ and limited to fields of less than $100 \mathrm{kG}^{3}$ The brittle A15 intermetal1ic compounds have been observed to have good properties at magnetic fields over $200 \mathrm{kG}$ and temperatures over $20^{\circ} \mathrm{K}$. The parameters that control the transition from the superconducting to nomal state (critical current, critical temperature and magnetic field) have been used to evaluate many binary and temary systems.

Matthias, et a1. 4 discovered the high cxitical temperature of $\mathrm{Nb}_{3} \mathrm{Sn}\left(18.05^{\circ} \mathrm{K}\right)$ in 1954, and Kunz1er ${ }^{5}$ reported its high field characteristics. New production methods have been developed to make it commercially available. In 1967 Matthias, et al. ${ }^{6}$ also found a superconductor with a $20.05^{\circ} \mathrm{K}$ critical temperature: $\mathrm{Nb}_{3}\left(\mathrm{Al}_{0.8} \mathrm{Ge}_{0.2}\right)$, and L. D. Hartsough, et al. ${ }^{7}$ reported in 1968 its critical magnetic field 
$(\mathrm{J}=0)$ at above $220 \mathrm{kG}$. These latter two historical discoveries have motivated many scientists and engineers to seek viable methods for its fabrication. Superconductors based on the $\mathrm{Nb}-\mathrm{Al}-\mathrm{Ge}$ system are not yet commercially available.

As far as high field current carrying capacity is concerned the method of high-rate sputtering shows ${ }^{8}$ very promising results: $2.5 \times 10^{5} \mathrm{amps} / \mathrm{cm}^{2}$ at $100 \mathrm{kG}$ and $2.6 \times 10^{4} \mathrm{amp} / \mathrm{cm}^{2}$ at $200 \mathrm{kG}$. This method however is limited to the production of rather thin films. Powder metallurgy approaches have been investigated in the past four years. R. Lohberg, et a1. prepared ribbons of composition $\mathrm{Nb}_{3} \mathrm{Al}_{0.7} \mathrm{Ge} 0.25$ by swaging, rolling and heating treatment. $\mathrm{J}_{\mathrm{C}}$ was in the order of $0.8 \times 10^{4} \mathrm{amp} / \mathrm{cm}^{2}$ at $150 \mathrm{kG}$. J.A. Cave, et al. 10 studied the A15 formation and its $\mathrm{T}_{\mathrm{C}}$ by sintering compacts of mixed elemental powders at temperatures between $1400-1800^{\circ} \mathrm{C}$ for periods of up to $120 \mathrm{~min}$.

In the present work a different powder metallurgy approach is described, as we11 as measurements of the superconducting properties of multifilamentary $\mathrm{Nb}-\mathrm{Al}-\mathrm{Ge}$ conductors. 


\section{OBJECTTVES}

In recent years powder metallurgy approaches to the production of $\mathrm{Nb}-\mathrm{Al}$-Ge superconductors have been studied; however a useful multifilamentary arrangement has not been reported. This has been the motivation to use a powder metallurgy method originally developed at our laboratories and successfully applied to $\mathrm{Nb}-\mathrm{Sn}$ system. The addition of a third element and the different properties of $\mathrm{Al}$ and Ge transform this study into a completely different problem.

In order to obtain the $A_{3} B$ type of compound, the method consists of isostatically compacting powder of element $A$ in the form of a rod, and sintering under conditions which yield a controlled porosity. Infiltxation with element $B$ into the interconnected pores and mechanical deformation produce a multifilamentary composite. The Al5 phase is produced by a diffusion heat treatment.

Taking into consideration that $\mathrm{Al}$ and Ge form an eutectic of relatively low melting point $\left(424^{\circ} \mathrm{C}\right)$, it can be infiltrated into a porous niobium rod, and the resulting composite can be mechanically processed. The principal objective is then to analyze the design parameters involved in the process as well as to measure the superconducting properties. 


\section{TIT. EXPERTMENTAL METHODS}

A. Equipment and Materials

The process described below involves the use of a high pressure isostatic press for niobium powder compaction, a high temperature furnace for sintering, a molten Al-Ge bath for infiltration, a form rolling machine for mechanical deformation, and a heat treating furnace for carrying out the diffusion reaction. Metallography was used for identification of the superconducting compound.

The materials used were high purity niobium powder of two particle size ranges: $-270+325$ mesh and $-325+400$ mesh; aluminum rod of $99.999 \%$ purity and germanium bars of $99.99 \%$ purity. During mechanical deformation hard drawn copper tubes were used as a cladding material. Details on these materials are given in Table 1.

B. Preparation and Characteristics of Aluminum-Germanium Eutectic

1. Metallography

The phase diagram in Fig. 1 shows an eutectic at $53 \%$ (weight) germanium, $47 \%$ (weight) aluminum at a temperature of $424^{\circ} \mathrm{C}$.

In preliminary experiments alloys were prepared from germanium and aluminum powder. Fig. 2-a shows the microstructure that results from mixing the two powders and melting them at $1100^{\circ} \mathrm{C}$ for 20 minutes. A great deal of porosity and many inclusions are present due to the oxide layers on the germanium and aluminum particles. In a second method, arc melted buttons made from solid $\mathrm{Al}$ and $\mathrm{Ge}$ in an argon atmosphere showed a microstructure similar to that of Fig. 2-d with small lamellae due to the fast cooling provided by the chilled copper surface in which they were prepared. Next the eutectic alloy was prepared in an 
induction furnace in the form of $10^{\prime \prime} \times 1 / 2^{\prime \prime}$ rod. Fig. 2 -b shows the microstructure of this material. No porosity or inclusions are noticeable.

It is interesting to see how the microstructure and lamella size change with different cooling rates. Figures $2-\mathrm{c}$ and $2-\mathrm{d}$ indicate the microstructure of samples prepared by the latter method: slowly cooled and quenched from $700^{\circ} \mathrm{C}$ respectively. In the first case the lamella size is approximately 2.5 microns while in the quenched sample it is only 0.75 microns.

The cooling rate has a strong effect on the microstructure and on the mechanical properties. In the as cast sample shown in Fig. 3-a the eutectic microstructure is very hard to distinguish. It is so hard and brittle that it will shatter if dropped. Measurements of its microhardness are discussed below. In Fig. 3-b the relative concentration of the two elements is shown (as analyzed by the SEM and EDAX. output).

From the as cast rod twelve samples were prepared; half of them were to receive a fast cooling rate from several temperatures (salt water quenching) and the rest a slow cooling rate (enclosed in quartz tubes, heated for 5 minutes and slow cooled). Figures 4 and 5 demonstrate the different changes. Figures $4-\mathrm{a}$ and $4-\mathrm{c}$ are microstructures from samples slow cooled from $700^{\circ} \mathrm{C}$ and $600^{\circ} \mathrm{C}$ respectively. Figures $4-\mathrm{b}$ and $4-\mathrm{d}$ correspond to samples quenched from the same temperatures. It is easy to notice the tremendous difference in the lamella size between a slow cooled and quenched sample at $700^{\circ} \mathrm{C}(5.5$ microns average in the first case to 1.5 microns average in the second). A similar difference occurs at $600^{\circ} \mathrm{C}$. 
At $500^{\circ} \mathrm{C}$, approaching the melting point of the a11oy $\left(424^{\circ} \mathrm{C}\right)$, the change in the microstructure between a slow cooled sample Fig. 5-a and a quenched sample Fig. 5-b is more difficult to see. The microstructures are very similar, indicating very little influence of the cooling rate at temperatures close to the melting point of the eutectic.

It is interesting to see what happens at temperatures below the melting point, for example $400^{\circ} \mathrm{C}$. Figure $5-\mathrm{C}$ shows the slow cooled and 5 -d the quenched microstructure of samples that had been heated for 5 minutes at $400^{\circ} \mathrm{C}$. In these samples the characteristic lame1lar structure of the eutectic composition is not present; rather the germanium has tended to spherodize.

These differences in the microstructure at the same composition suggest a probable effect on the mechanical properties.

2. Microhardness Measurements

Vickers pyramid microhardness measurements have been made on all the previously discussed samples, using a $500 \mathrm{gm}$. 1 oad for the indentations that were larger than 50 microns (the minimm value for accurate measurements.)

The heavy load was chosen in ordex to obtain indentations that cover a whole area of A1-Ge eutectic and not only the individual elements.

These results (Fig. 6) show that generally the quenched samples which produce finer microstructures also have a higher microhardness. The as cast samples have a very high value of 260.4 (not shown in the plot) and next, those quenched from $900^{\circ} \mathrm{C}$ and $800^{\circ} \mathrm{C}$ with values of 128.5 and 129.9 . This shows a decrease to almost $1 / 2$ of the as cast value. 
A similar behavior when the eutectic is present in an infiltrated sample, discussed later, camot be expected due to the fact that at temperatures over $650^{\circ} \mathrm{C}$ and for the infiltration times employed the A1-Ge eutectic alloy reacts with the niobium matrix producing a hard temary intermetallic AI rich compound. At lower temperatures of infiltration though, this intermetallic is practically eliminated; therefore, the results of this study become relevant.

The previous study suggests that heat treating of the Al-Ge eutectic alloy can be beneficial. At $400^{\circ} \mathrm{C}$ it has its lowest values of microhardness and consequently may lead to higher ductility. This however should be further investigated with infiltrated $\mathrm{Nb}$ rods.

C. Process Stages

The process discussed below is shown schematically in Fig. 7 .

1. Isostatic Compaction of Niobium Powder

Powders of two size ranges $(-270+325$, and $-325+400$ mesh $)$ selected from the vibrating sieves were isostatically compacted in rubber molds at $35,000 \mathrm{psi}$, resulting in self-supporting rods. These roads were of two size: $0.220^{\prime \prime}$ OD and $0.156^{\prime \prime}$ OD.

\section{Sintering}

The hydrostatically pressed rods were sintered in vacuum in the Abar furnace shown in Fig. 8. The samples (6) were heated to 2250$2300^{\circ} \mathrm{C}$ for 15 minutes by a resiscively heated tungsten element (5). The temperature was recorded by means of a thermocouple (9) close to the element; for this reason enough time (6-10 minutes) was necessary to stabilize the temperature. 
The result of the sintering is a self-supporting rod with ductile characteristics and a network of interconnected pores. Scanning electron micrographs of a sintered niobium rod are shown in Fig. 9 a-b. It is possible to appreciate the pores at a high magnification of a cross section. Brittle fracture was performed prior to this examination. Figure 9-b shows the bonding of the particles.

A variable that can be controlled during the sintering stage is the porosity. This may be accomplished by controlling the time of sintering or the particle size. In this case the time of sintering was maintained constant but two particle sizes were used, $-270+325$ and $-325+400$ mesh The results are noticeable during infiltration as described in the next step.

\section{Infiltration with $\mathrm{Al}-\mathrm{Ge}$}

Using the same set up in the Abar fumace the liquid Al-Ge eutectic was placed in a $16 \mathrm{~mm}$ OD quartz tube (13) Fig。 8 which was surrounded by a graphite crucible to hold the quartz tube and at the same time act as a heat conductor. The heat source was an external resistive heating element (14) with a thermocouple attached to register the temperature.

The infiltration is done after sintering and slow cooling of the sample, while still inside the tungsten element, down to $100^{\circ} \mathrm{C}$. This is to prevent instantaneous solidification of the eutectic and to maintain its viscosity which is necessary for the capillary forces to be effective in causing the flow of the liquid metal into the interconnected pores of the sintered niobium. 
Preliminary infiltration experiments were carried out at temperatures of $750^{\circ} \mathrm{C}$ and $700^{\circ} \mathrm{C}$. Figure 10 -a shows a cross section of a rod infiltrated at $700^{\circ} \mathrm{C}$ for one minute. In this photomicrograph are present: the eutectic Al-Ge microstructure (1); A1 solid solution (2); and $\mathrm{Al}$ rich intermetallic compound $\mathrm{Nb}(\mathrm{Al} \mathrm{Ge})_{3}$ (3) which is the result of diffusion reaction during infiltration at that temperature and time; and the niobium matrix (4).

The A1-Ge used here came from arc melted buttons as previously described to which $(1-3 \%)$ excess Al was added to the eutectic $(47 \% \mathrm{Al}$, $54 \% \mathrm{Ge}$ ) with the idea of compensating for evaporation of $\mathrm{Al}$ during arc melting. It was observed however that Al losses during arc melting were negligible, less than $0.5 \%$. For this reason there is free $A 1$ solid solution after infiltration.

These preliminary experiments indicate the need for controlling several variables. First the exact composition of the Al-Ge eutectic so there is no free A1 present. Second, lowering the temperature of infiltration in an attempt to eliminate the formation of the $\mathrm{Nb}(\mathrm{Al} \mathrm{Ge})_{3}$ phase which, due to its intermetallic nature, is hard, brittle and consequently detrimental to mechanical deformation. For this reason infiltrations at $650^{\circ} \mathrm{C}, 600^{\circ} \mathrm{C}, 550^{\circ} \mathrm{C}$ and $500^{\circ} \mathrm{C}$ were carried out with 0.156 diameter sintered niobium rods. These were infiltrated for two and a half minutes and two were tried at $500^{\circ} \mathrm{C}$ for one minute. It is important to mention that for the infiltrations at higher temperatures $\left(750^{\circ} \mathrm{C}, 700^{\circ} \mathrm{C}\right)$ half an hour was required for the eutectic to melt and reach a stable temperature. At lower temperatures $-550^{\circ} \mathrm{C}$ and $500^{\circ} \mathrm{C}-$ it required at least one and a half hours to melt the eutectic and one more hour to stabilize the temperature. 
Figure $10-\mathrm{b}$ shows a cross section of a sample infiltrated at $500^{\circ} \mathrm{C}$ for two and a half minutes in which the intermetallic Al rich phase has been eliminated from the eutectic microstructure. These rods were easier to deform than the previous ones.

Another variable mentioned previously, while discussing the sintering process, was the powder particle size. Figure 11-a shows infiltration at $700^{\circ} \mathrm{C}$ for one minute with powder of $-325+400$ mesh, while Fig. 11-b shows infiltration at $500^{\circ}$ for two and a half minutes with powder $-270+325$ mesh. In the first case the pores are generally smaller than in the second. Both of then have the same sintering time and temperature (10 minutes at $2250^{\circ} \mathrm{C}$ ).

\section{Mechanical Deformation}

Form rolling, flat rolling, swaging and wire drawing were used with different results for the superconducting properties, especially the current carrying capacity. Wire drawing was favored over form rolling and the latter was better than swaging for niobium - tin composites. 11 This is probably due to the nature of the mechanical deformation process. Wire drawing and form rolling will tend to produce parallel filaments, while swaging will introduce a twist due to the rotating hammers and consequently that affects the contimuity of the filaments.

It is possible that the same processes could be applied to the $\mathrm{Nb}-\mathrm{Al}-\mathrm{Ge}$ system under certain conditions; however experiments carried out in the present study with all these processes have favored combinations such as, form rolling and swaging, form rolling and flat rolling and finally form rolling only. 
For wire drawing, infiltrated rods were enclosed in a $0.250^{\circ}$ OD tantalum tube and this assembly was enclosed in a $0.375^{\circ}$ OD Cumi tube, as a first experiment. With this arrangement a reduction to $0.090^{\prime \prime}$ on was possible. A second experiment had the same nominal dimensions of the previous one both this time a $\mathrm{Nb}$ tube was used instead of $\mathrm{Ta}$ and pure $\mathrm{Cu}$ instead of $\mathrm{Cu}-\mathrm{Ni}$. This arrangement made possible a reduction only to $0.124^{\prime \prime}$ OD. The reduction ratio (initial cross section area to final cross sectional area) was 17.3 in the first case and 9.1 in the second. Metallographic inspection of these wires showed fracture starting at the center of the core and propagating towards the outside. This leads to the conclusion that the tension introduced during wire drawing far exceeded the tensile strength of the infiltrated core. Form rolling and swaging were successful in reducing down to $0.060^{\circ}$ but showed a detrimental influence of the twisting action in small sections, such as $0.020^{\circ}$.

Combination of form rolling and flat rolling lead to the production of tapes as thin as $0.008^{\prime \prime}$. These samples had the infiltrated rod surrounded by an inner tantalum tube and an outer Monel 400 tube. After they were form rolled down to $0.250^{\prime \prime} \times 0.250^{\prime \prime}$ sections, the monel was removed by etching in nitric acid and then they were flat rolled to the small size indicated above. 12

The necessity for reducing the infiltrated rods to such small sizes is based on the stability of a superconductor: the ability to operate in an applied magnetic field in such a way that any perturbation of conditions causing motion of flux lines will not generate enough heat 
to drive the superconductor nomal. Smith ${ }^{8}$ criterion $^{11}$ which assumes no heat loss from the superconductor during a perturbation, limits the filament size to the order of a few microns. Even though flat rolling produces filaments of the order of $2-5$ microns thick their width may be much greater. For this reason a process that controls both the filament thickness and width is more desirable.

With this idea in mind a wire may make an intrinsically stable conductor. In the present study, as mentioned above, direct wire drawing did not seem to be a solution. Form rolling only, appeared to be a feasible process.

Two form rolled configurations were made. The first one, a $0.156^{\circ}$ OD infiltrated $\mathrm{Nb}$ rod, was surrounded by a $\left(0.250^{\circ} \mathrm{OD}, 0.030^{\circ}\right.$ wa11) niobium tube, and an outer $\left(0.375^{\circ} \mathrm{OD}, 0.065^{\circ}\right.$ wall) hard drawn copper tube. This configuration was form rolled in a machine shown in Fig. 12-a. The last pass produced a composite $0.125^{\circ} \times 0.125^{\circ}$. A second enclosure of this arrangement in a $\left(0.250^{\circ} 00,0.065^{\circ}\right.$ wa11) hard drawn copper tube, followed by form rolling to the smallest groove, deformed the $\mathrm{Nb}$ inner tube and the infiltrated rod to a small size wire $0.025^{\circ} \times 0.025^{\prime \prime}$. As a result the intercomected filaments were $1-4$ microns as shown in Fig. 12-b.

The second configuration was made by a similar procedure. This time the $\mathrm{Nb}$ tube was eliminated and only the infiltrated rod was form rolled in a hard drawn copper tube. The initial configuration consisted of a $0.250^{\prime \prime}$ OD, $0.035^{\circ}$ wall hard drawn copper tube and a $0.156^{\prime \prime}$ OD infiltxated core. After passing through the last groove - $0.125^{\circ} \times 0.125^{\prime \prime}$ nominal size -. the composite was enclosed in another hard drawn copper tube, 
$0.250^{\prime \prime} \mathrm{OD}$, heavy wa11 $0.065^{\prime \prime}$, and deformed again to the last groove. As a result the inside core conductor had a $0.022^{\prime \prime} \times 0.022^{\prime \prime}$ section. In both cases the outer copper sheath was etched in nitric acid leaving the small conductors shown in Fig. $13 \mathrm{a}$-d. The first case Fig. $13 \mathrm{a}-\mathrm{b}$ has the $\mathrm{Nb}$ tube surrounding the core and the second, Fig. $13 \mathrm{c}-\mathrm{d}$ has only the infiltrated core.

The reason for eliminating the niobium outer sheath was that it caused poor electric contacts for measuring the superconducting properties and possible problems in evaluating $\mathrm{J}_{\mathrm{c}}$ due to current sharing of the $\mathrm{Nb}$.

It is noteworthy that both samples can be bent to a radius of $0.5 \mathrm{~cm}$.

5. Diffusion Heat Treatment

Muller ${ }^{13}$ investigated the range of existence of the A15 phase in the system $\mathrm{Nb}-\mathrm{A} 1-\mathrm{Ge}$ at $1840^{\circ} \mathrm{C}$ and concluded that the A15 phase occurred in three two-phase fields with A2 (niobium solid solution) phase, $\sigma$ phase $\mathrm{Nb}_{2}(\mathrm{Al} \mathrm{Ge})$ and $\mathrm{Nb}_{3}(\mathrm{Al} \mathrm{Ge})_{3}$ as a structural partner. His temary phase diagram at this temperature is presented in Fig. 14.

In the present study two series of experiments have been carried out. First, samples infiltrated but non-deformed have been reacted at high temperatures: $1300^{\circ} \mathrm{C}$ and above. A second series of samples which were form rolled by the process previously described were reacted at different temperatures for short periods of time.

The photomicrograph (Fig. 15-a) taken at high magnification in the (SEM) shows a sample of the first series, reacted at $1700^{\circ} \mathrm{C}$ for one 
minute. There are four regions that can be distinguished in different levels, due to the etching solution used (equal volumes of hydrofluoric acid, sulfuric acid and water to which several drops of hydrogen peroxide were added). ${ }^{14}$ The first region starting from the center corresponds to a Ge rich phase (1) identified as $\mathrm{Nb}_{5}(\mathrm{Ge} A \mathrm{Al})_{3}$ with atomic percent as $\mathrm{Nb}_{51.8} \mathrm{Al}_{14} \mathrm{Ge}_{34}$ determined by the (SEM) computer display. A graphical representation of this relative concentration is shown in Fig. 15-b. The second region from the center (2), an $\mathrm{A}$ rich phase, is identified as the o phase $\mathrm{Nb}_{2}(\mathrm{Al} \mathrm{Ge})$. Fig. 15-c shows its relative concentration; its atonic percent is $\mathrm{Nb}_{70}, 6^{\mathrm{A1}} 21.0^{\mathrm{Ge}_{8.2}}$. The third region (3) of Fig. 15-a is the A15 phase which appears deeper than the others because it is more sensitive to the etching solution. The atomic percentage of this phase is $\mathrm{Nb}_{80.6^{A}} 1_{13.1} \mathrm{Ge}_{6.1}$ (Fig. 15-d). Finally the fourth (4) region at the edge is identified as the A2 phase, $\mathrm{Nb}$ solid solution (body centered cubic niobium with mainly aluminum and smaller amount of gemanium in solid solution). For this region the atomic percentage is $\mathrm{Nb}_{91.1} \mathrm{Al}_{7.2} \mathrm{Ge}_{1.58}(\mathrm{Fig} .15-\mathrm{e})$. Another measurement of the concentration further out in the $\mathrm{Nb}$ had atomic percentages of $\mathrm{Nb}_{97.8}{ }^{\mathrm{Al}} \cdot{ }_{72} \mathrm{Ge}_{1.4}$ indicating practically all $\mathrm{Nb}$ matrix.

A sample deformed and reacted was analyzed by the same method (SEM) and EDAX. The results are shown in Fig. 16. In the three regions indicated in Fig. 16-a, (1) is the Ge rich phase $\mathrm{Nb}_{5}(\mathrm{Ge} A 1)_{3}$. Its relative composition is shown in Fig. 16-b. Region (2) is the A15 phase which appears in the form of filaments and region (3) is the $\mathrm{Nb}$ solid solution $\mathrm{A} 2$. Their relative concentrations are indicated in 
Figs. 16-c and 16-d respectively. The electron beam scans are shown in Fig. 16-a for the aluminum and germanium concentrations.

The A15 lattice parameter was measured by X-ray diffraction techniques for the sample shown in Fig. 16-a and an average value was obtained in the order of $5.176 \pm 0.005$ which is in agreement with the investigations done by $\mathrm{G}$. Arrhenius. 15

After this basic analysis was completed, samples such as the ones shown in Fig. $13 \mathrm{c}-\mathrm{d}$, with dimensions $0.022^{\prime \prime} \times 0.022^{\prime \prime}$, were reacted at different temperatures and times, as shown in Table II in order to measure the superconducting properties. Temperatures in the range of $1300^{\circ} \mathrm{C}$ to $1750^{\circ} \mathrm{C}$ were tried for three periods of time: $15 \mathrm{sec}$, 1. minute and $21 / 2$ minutes. The superconducting properties will be discussed after a consideration of the microstructures.

Figures 17-20 show the microstructures obtained after these treatments.

Figures 17 and 18 correspond to the longest heat treatment, $21 / 2$ minutes at $1750^{\circ} \mathrm{C}$ and at $1300^{\circ} \mathrm{C}$ respectively. In the first case, Fig. 17-a, a longitudinal section is shown. The average filament thickness is about 18 microns. It is possible by using an etch and anodizing technique to recognize the different phases and also the large grains that result at this high temperature as shown in Fig. 17-a. The etching solution ${ }^{14}$ used after the samples were polished with aluminum oxide was the same used for the previous analysis of reacted non-deformed samples (Fig. 15-a). Two anodizing solutions were used in order to identify the phases after etching. The first was an 
aqueous ammonia solution (15\%) with five minutes anodizing at $30 \mathrm{~V}$. 13 The other solution was Picklesimer"s ${ }^{16}$ with which anodizing was carried out for five minutes at $27 \mathrm{~V}$.

The ammonia solution identifies the phases as A2: gray-white; A15 phase: light blue; $\mathrm{Nb}_{2}\left(\mathrm{Al}\right.$ Ge) o phase: blue; $\mathrm{Nb}_{5}(\mathrm{Ge} \mathrm{Al})_{3}$ : dark blue $^{13}$. The second solution was used in order to produce a better contrast for photography. It produces shades from a light blue A2 to a dark purple $\mathrm{Nb}_{5}(\mathrm{Ge} \mathrm{Al})_{3}$, leaving intermediate shades for the other two phases.

A11 these four phases are present in Fig. 17-a, but the AI and Ge rich phases are in small proportion compared with the A15 and Nb matrix. Figure 17-b was used to evaluate the A15 volume fraction. A statistical technique was used in a $9 \mathrm{~cm} \times 11 \mathrm{~cm}$ area of the photomicrogxaph. A scale with $5 \mathrm{~mm}$ divisions in both directions was superimposed on the photo dividing the area in $5 \times 5 \mathrm{~mm}$ squares. The total number of intersecting points between vertical and horizontal lines was 437. By using carbon paper in between, points corresponding to the A15 phase on the photo, were recorded on a paper placed underneath. A count of these points was related to the total ( 437 points) in order to obtain the A15 volume fraction. This heat treatment produced $51.9 \%$ A15 phase. The same techniques were employed for Fig. 18-a, a longitudinal section and $18-b$, a cross section. This time the heat treatement was made at the lower temperature, $1300^{\circ} \mathrm{C}$, for the same time, $21 / 2$ minutes. Here the average filament size is 7.2 microns. The same four phases are present as shown in Fig. 17-a. 
In the cross section, Fig. 18-b, it is worth noticing the greater percentage of the dark phases when compared with Fig. 17-b. It is possible to see how the A15 grows at the expense of the other two phases. The A15 volume fraction for this heat treatment was $32.12 \%$.

The short heat treatment (15 seconds) is also analyzed in Figs. 19 and 20 for $1750^{\circ} \mathrm{C}$ and $1300^{\circ} \mathrm{C}$ respectively. In the first case there is a greater percentage of A15 $(38.4 \%)$, a larger filament size (9.6 microns average) and also four phases; however the dark phases are present in less amount than in Fig. 17-b and consequently there is more A15 phase.

Fina1ly in the lowest extreme of time and temperature, Fig. 20-a and 20-b, very small filaments are observed (5.01 microns average). It will be shown later that this has a great influence on the superconducting properties. The four phases are still present although it is more difficult to distinguish between the two tones of the darker phases. The A15 volume fraction is much less (21.25\%)。

It is worth mentioning that there seems to be a greater influence of temperature than of time in the formation of the A15 phase. If we compare $1750^{\circ} \mathrm{C}-15 \mathrm{sec}$ (Fig. 19) and $1300^{\circ} \mathrm{C}-21 / 2 \mathrm{~min}$. (Fig. 18) the first one has a greater percentage of the A15 (38.4\%) phase than the second (32.12\%) and also the filament size is 1.25 times larger. With these considerations, lower temperatures and shorter time seem to favor the control of the filament size necessary for the stability of the superconductors for a given amount of reduction as mentioned earlier. 
D. Determination of Superconducting Properties

1. Critical Current Measurements

The pulsed magnet technique was employed in order to evaluate the critical current at high fields. The equipment is capable of producing pulsed fields over 100kG. The method for measurement is described in Chabanne $^{17}$ and Garrett. 18 The time for the pulse to xise from zero field to peak is approximately eight milliseconds. 11

After specimens were mechanically deformed, bent and the outer copper sheath etched away they were cut to fit the dimensions of the probe. As stated previously some samples have an outer sheath of Nb as shown in Figs. $13 \mathrm{a}$-b or no cladding as in Figs. $13 \mathrm{c}$-d. In either case the metals are not easy to solder as required to mount them on the pulse magnet probe. This is attributed to the stability of the Ta and $\mathrm{Nb}$ oxides on the surface of the samples. For this reason thin copper plates were spot welded on each side of the sample so that tin solder could be used to provide good electric contact with the probe. A typical oscilloscope display is shown in Fig. 21-b, with an explanatory graph, Fig. 21-a 11 . There are three recordings: sample current, sample voltage and the magnetic field. $\mathrm{H}_{1}$ and $\mathrm{H}_{2}$ indicate the beginning and the end of the transition for the values of the magnetic field recorded in the bottom curve.

In the graphs of Figs. 22-24 the overall critical current density is plotted as a function of the transverse magnetic field. This assumes the current is carried over the whole cross sectional axea $31.2 \times 10^{-4}$ $\mathrm{cm}^{2}\left(4.84 \times 10^{-4} \mathrm{in}^{2}\right)$ 
In order to obtain each one of the plotted points, the samples were attached to the pulse magnet probe with tin solder. The probe was cooled in liquid nitrogen before placing it in the superconducting magnet that was immersed in liquid helium.

With this arrangement the magnetic field is perpendicular to the transport current. The magnetic field strength was set and the sample current was increased until the transition to the normal state occurred. The current and the voltage drop were recorded at the same time in a Clevit-Brush 6-channe1 recorder with maximum sensitivity of $1 \mathrm{uV}^{11}$.

2. Transition Temperature Measurements

The inductive method was used for measuring the transition temperature. This implies that the self-inductance and frequency of the coil placed in the probe changes as the magnetic permeability of the samples changes when the temperature rises and drives the samples noma1. The probe is immersed in liquid helium and the temperature rise is controlled by a Manganin wire heater. 11

The temperature was detected by an $\mathrm{Au}-\mathrm{Au}+7$ at: $\mathrm{Fe}$ thermocouple. The frequency shift and the change in temperature were plotted on a chart recorder. The transition temperature was taken at the midpoint of the frequency shift and plotted in Figure 26. The values are in agreement with the one reported in the literature. 19,20

Due to the configuration of the filaments they are not expected to have the high $\mathrm{T}_{\mathrm{C}}$ values of the arc melted samples reported by Mathias, $20.05^{\circ} \mathrm{K}^{6}$ This has been confirmed by J. Ruzicka ${ }^{21}$ who compared severa1 methods. For example $\mathrm{T}_{\mathrm{c}}$ measured on laminated $\mathrm{Nb}_{3} \mathrm{Al}_{0.8} \mathrm{Ge}_{0.2}$ strips varies between $18^{\circ}$ and $19^{\circ} \mathrm{K} . \mathrm{Nb}_{3} \mathrm{Al}_{0.75^{\mathrm{Ge}}} 0.25$ ribbons prepared by 
swaging and rolling cupronickel tubes filled with $\mathrm{Nb}, \mathrm{Al}$, Ge powders and then annealing after the $\mathrm{Cu}-\mathrm{Ni}$ had been etched away have shown $\mathrm{T}_{\mathrm{C}}$ values of $17.3-19^{\circ} \mathrm{K}^{9}$ Thin films obtained by sputtering from a hot pressed target having a composition corresponding to $\mathrm{Nb}_{3} \mathrm{Al}_{0.8} \mathrm{Ge}_{0.2}$ had a $\mathrm{T}_{\mathrm{C}}$ of $16^{\circ} \mathrm{K} .{ }^{22}$ For $\mathrm{Nb}-\mathrm{Al}-\mathrm{-Ge}$ films prepared by simultaneous vacuum vapor deposition of the individual elements a $\mathrm{T}_{C}$ of $17.8^{\circ} \mathrm{K}$ was reported. 23 


\section{RESULTS AND CONCLUSIONS}

\section{A. Processing}

The powder metallurgy infiltration method originally employed to produce $\mathrm{Nb}$-Sn multifilamentary superconductors has successfully been applied to the preparation of multifilamentary tapes and form rolled wires in the $\mathrm{Nb}-\mathrm{Al}$-Ge system. Although there is much similarity between the two processes, the nature and different properties of the elements used leads to variations in the control of the parameters.

The preparation of the AI-Ge eutectic by means of an induction furnace in the form of rods $0.5^{\prime \prime}$ OD $\times 8^{\prime \prime}$ long gives a clean alloy, oxide free, with good homogeneity and the desired composition.

The isostatic compaction of the two powder sizes employed $(-325+400$ and $-270+325)$ offers no major difficulty.

The sintering and infiltration steps must be carried out with no interruption. This means that once the $\mathrm{Nb}$ powder rod has been sintered

(in vacuum $1-5 \times 10^{-5} \mathrm{~mm} \mathrm{Hg}$ ), the 1iquid eutectic alloy underneath must be ready for infiltration at the desired temperature $\left(500^{\circ} \mathrm{C}\right)$. These two steps cannot be interrupted because during sintering the oxides on the particle surfaces are eliminated. This provides good wetting conditions. If infiltration is done after the sample has been exposed to air or even He gas, the wetting conditions are deteriorated due to the stability of the oxides formed. Once the sintered rod is immersed in the eutectic alloy a back pressure - helium was used in the present experiments - - is necessary for full infiltration. This pressure is usually on the order of $-10 \mathrm{~mm} \mathrm{Hg}$. 
The capacity for mechanical deformation seems to depend on the infiltration temperature. As mentioned previously, intermetallic phases in samples infiltrated at $500^{\circ} \mathrm{C}$ are not present, while at $700^{\circ} \mathrm{C}$ they are. These intermetallics keep a round shape that tears the niobium matrix during mechanical deformation. For this reason uniform filaments were obtained in mechanically deformed samples which originally were infiltrated at lower temperatures. The form rolling process as used here with an outer sheath of hard drawn copper has been explored further by enclosing the composite in copper tubing $0.250^{\circ} \mathrm{OD}, 0.065^{\circ}$ wall three times after form rolling to the smallest groove. When the $\mathrm{Cu}$ is etched a $0.010^{\prime \prime} \times 0.010^{\prime \prime}$ form rolled wire remains. This wire is more flexible and contains smaller filaments (less than 4 microns). The form rolling process as used here may be a good way to produce long length multifilamentary wires. If instead of square shapes, as the ones reported here, a round shape is desired, this could be accomplished by changing the shape of the grooves in the form rolling machine.

With the heat treatments reported (as shown in Figs. 17-20) the filament size can be controlled by time and temperature. There seems to be a more critical influence of temperature than of time on the filament growth as previously mentioned.

B. Properties of Al-Ge Eutectic Alloy

The microhardness measurements on the eutectic alloy are summarized in Fig. 6. The microhardness of quenched samples increases as the quenching temperature increases, and reaches a maximum value between $800^{\circ} \mathrm{C}$ and $900^{\circ} \mathrm{C}$. An alternative of a fast cooled sample is the as 
cast condition which showed a Vickers microhaxdness of 260.4 , a very high value compared to the other two $\left(800^{\circ}-900^{\circ} \mathrm{C}\right)$.

For the slowly cooled samples the microhardness does not change appreciably up to approximately $630^{\circ} \mathrm{C}$, but increases for the higher temperatures.

It is possible to change the microstructure of the eutectic alloy by thermal treatment. This opens the question whether it is possible to change its ductility. The answer seems to lie in low temperature heat treatments and low temperatures of infiltration. This is an area that can be explored further.

\section{Critical Currents}

Analyzing the results that appear in Figs. 22-25 is important for evaluating this method of producing multifilamentary superconductors. There seems to be a similar pattern for the samples heat treated at different times (15 sec, 1 min. and $21 / 2$ minutes). This means that samples heat treated at lower temperatures show better current carrying capacities at high magnetic fields than the ones heat treated at high temperatures.

If a comparison is made between Figs. $22,23,24$ in which the overall critical current density has been evaluated, it is possible to see the influence of the heat treatment time on the critical current. For a specific value of the field, $60 \mathrm{kG}$ for example, at $1300^{\circ} \mathrm{C}$ a sample heat treated for $15 \mathrm{sec}$. will carry $0.78 \times 10^{4} \mathrm{amp} / \mathrm{cm}^{2}$, and at $21 / 2$ min. will carry $0.55 \times 10^{4} \mathrm{amp} / \mathrm{cm}^{2}$. At the same field, a sample heat treated at $1750^{\circ} \mathrm{C}$ for $15 \mathrm{sec}$. will carry $0.23 \times 10^{4} \mathrm{amp} / \mathrm{cm}^{2}$, for $1 \mathrm{~min}$, 
$0.13 \times 10^{4} \mathrm{amp} / \mathrm{cm}^{2}$, and for $21 / 2 \mathrm{~min}$. will have been driven completely normal.

Improved values of $\mathrm{J}_{\mathrm{c}}$ for a sample heat treated at $1300^{\circ} \mathrm{C}$ for $21 / 2$ min. are shown in Fig. 22. This has been achieved by a post heat treatment at $750^{\circ} \mathrm{C}$ for 96 hours. At $60 \mathrm{kG}$, the field used for comparison, it wi11 carry $0.68 \times 10^{4} \mathrm{amp} / \mathrm{cm}^{2}$-better than the one with no post heat treatment, but low in comparison with the one heat treated at $1300^{\circ} \mathrm{C}$ for 15 seconds.

This discussion suggest four major conclusions. First the highest current carrying capacity corresponds to the lowest temperature employed, $1300^{\circ} \mathrm{C}$, and gradually degrades as the tempexature goes up. Second, samples reacted for short periods of time $\left(15\right.$ sec.) show a better $J_{C}$ and degrades as the hear treatment time increases to $21 / 2$ minutes. At high temperatures $\left(1750^{\circ} \mathrm{C}\right)$, a $21 / 2 \mathrm{~min}$. treatment will cause the sample to be driven nomal at $22 \mathrm{kG}$. Third, the $\mathrm{J}_{\mathrm{c}}$ follows an inverse relation with the filament size and the A15 volume fraction as discussed in the previous section. Snaller filaments and low volume fractions are related to higher $J_{C}$. Finally the temperature seems to have more influence on the $J_{c}$ than the time of heat treatment. A sample at $1300^{\circ} \mathrm{C}$ for $21 / 2$ minutes carries $0.55 \times 10^{4} \mathrm{amp} / \mathrm{cm}^{2}$, while one heat treated at $1750^{\circ} \mathrm{C}$ for only 15 seconds carries $0.23 \times 10^{4} \mathrm{amp} / \mathrm{cm}^{2}$ a ratio of $2.4: 1$ at $60 \mathrm{kG}$.

So far, the overa11 values of $J_{c}$ have been discussed. Now, taking into consideration the Al5 volume fraction, $J_{C}$ values for four samples are plotted in Fig. 25. These samples are heat treated at the highest 
$\left(1750^{\circ} \mathrm{C}\right)$ and the lowest $\left(1300^{\circ} \mathrm{C}\right)$ temperatures used. Here the best sample as far as $J_{C}$ is concerned has been heat treated at $1300^{\circ} \mathrm{C}$ for only $15 \mathrm{sec}$. It carries $8.8 \times 10^{4} \mathrm{amp} / \mathrm{cm}^{2}$ at $20 \mathrm{kG}$ and $3.6 \times 10^{4}$ amp $/ \mathrm{cm}^{2}$ at $60 \mathrm{kG}$ - a value 4.6 times larger than the overall critical current at that field. The $J_{c}$ values decrease for a given field as the time of heat treatment and temperature increase. The A15 filaments and the microstructure of these four samples were previously shown in Figs. 17-20。

Finally, a comparison with values reported in the literature and obtained by other methods is important. In Table III the values of $J_{c}$ for three fields $(20,50$ and $60 \mathrm{kG})$ for four methods have been taken from J. Ruzicka ${ }^{21}$ who presented a comparison of his method (bulk samples) with others.

The overall $\mathrm{J}_{\mathrm{C}}$ of the sample heat treated at $1300^{\circ}, 15 \mathrm{sec}$, made by the infiltration method, shows superior values at the three fields mentioned as compared with bulk samples by Ruzicka, ${ }^{21}$ bulk samples by Hartsough ${ }^{7}$ and ribbons prepared by swaging and rolling Lohberg 9 and shows lower values when compared with evaporated thin films by Hammond. 23

\section{Critical Temperature}

Ixperimental $\mathrm{T}_{\mathrm{C}}$ data for samples heat treated for 15 seconds at various temperatures is presented in Fig. 26. The critical temperature increases as the reaction temperature increases.

A similar pattern in the increase of $\mathrm{T}_{\mathrm{C}}$ with the reaction temperature was reported by J.A. Cave, et a1. 10 who obtained values 
of $17.5^{\circ} \mathrm{K}$ for $1400^{\circ} \mathrm{C}, 18.5^{\circ} \mathrm{K}$ for $1602^{\circ} \mathrm{C}$ and $18.9^{\circ} \mathrm{K}$ for $1800^{\circ} \mathrm{C}$ for samples prepared by sintexing compacts of mixed elemental powders. According to $G$. Arrhenius, et a1. ${ }^{15}$ there are two factors that will determine the $\mathrm{T}_{\mathrm{C}}$. They are the number of valence electrons per atom and the degree of atomic order in the $A_{3} B$ compound.

With this in mind the lower values of $T_{C}$ of samples heat treated at lower temperatures can be explained. First the atomic mobility at higher temperatures may lead to a bettex arrangement of the $\beta-W$ structure required for good $T_{C}$. Second the stoichiometry may not be ideal for such short heat treatments. The best compositions are in the range $\mathrm{Nb}_{3}\left(\mathrm{Al},{ }_{75} \mathrm{Ge} .25\right)$ to $\mathrm{Nb}_{3}\left(\mathrm{AI} .70^{\mathrm{Ge}}{ }_{330}\right)$ where the value of $\mathrm{T}_{\mathrm{c}}$ is around $20.5^{\circ} \mathrm{K}^{15}$ At high temperatures such as $1840^{\circ} \mathrm{C}$ these compositions may not be completely ordered and therefore a secondary post heat treatment at $800^{\circ} \mathrm{C}$ was necessary to raise the $\mathrm{T}_{\mathrm{C}}$ from $19.3^{\circ} \mathrm{K}$ to $19.9^{\circ} \mathrm{K}$ as experienced in bulk samples by A. Muller. ${ }^{13}$ After heat treatment at $1600^{\circ} \mathrm{C}, \mathrm{T}_{\mathrm{C}}$ was raised from $18.0^{\circ} \mathrm{C}$ to $19.2^{\circ} \mathrm{C}$ by a post heat treatment at $760^{\circ} \mathrm{C}$ according to $\mathrm{E}$. Tanaka, et a1. 20

The values of $\mathrm{T}_{\mathrm{C}}$ for samples made by the infiltration method are comparable with the values reported in the literature. 
V. FUTURE STUDIES

There are three major areas investigated here that are interesting for future studies: (1) Further evaluation of the mechanical behavior of the A1-Ge eutectic a1loy; (2) Process refinement and (3) Improvements in the superconducting properties.

(1) The influence of heat treatment on the microstructure can be understood better if related to other properties such as tensile strength which is a limiting factor in wire drawing. The addition of other elements such as lead or tin to the Al-Ge eutectic as a future study may help with the ductility problem.

(2) Mechanica1 deformation processes such as high pressure cold hydrostatic extrusion have been successful in deforming materials with poor ductile properties. ${ }^{24}$ This can be a good alternative for this system.

(3) Further investigation in improving the current carrying capacity at high fields may make this system competitive with $\mathrm{Nb}-\mathrm{Sn}$. In order to achieve this, several identified variables can be considered. The improvement on $J_{C}$ by doping the $\mathrm{Nb}-\mathrm{Sn}$ system with $\mathrm{Zr}$ is well known; the influence of this on $\mathrm{Nb}-\mathrm{Al}-\mathrm{Ge}$ is not yet known. A precise control of the grain size as well as the filament size for various heat treatments could yield useful results to improve $\mathrm{J}_{\mathrm{C}}$ and $\mathrm{T}_{\mathrm{C}}{ }^{\circ}$ 


\section{ACKNOWLEDGEMENTS}

The author gratefully extends his thanks to Dr. Milton R. Pickus for his guidance, encouragement and evaluation throughout this research. Special thanks are due to Dr. Moshe Dariel for his helpful suggestions and constructive contribution in the evaluation of $\mathrm{X}$-ray diffraction and electron microscopy data. Fruitful discussions and comments from Dr. John Ling-Fai Wang are greatly appreciated.

I am indebted to Dr. Kanithi Hemachalam for his helpful comments on the manuscript and assistance in evaluating the superconducting properties. Thanks to Robert Ciardella for his assistance at the initial stages of this project.

The author would like to express special appreciation to Mr. John Holthuis for his technical assistance throughout his work, and to Mr. John Jacobsen for his assistance with the metallographic techniques.

This work has been accomplished under the auspices of the U.S. Energy Research and Development Administration through the Materials and Molecular Research Division of the Lawrence Berkeley Laboratory at the University of Califomia, Berkeley. 
REFERENCES

1. H. K. Onnes, Comm. Phys. Lab., Univ of Leiden, 119, 120, 122 (1911).

2. R. L. Ciardella, Design Parameters for Processing Flexible $\mathrm{Nb}_{3} \mathrm{Al}$ High Field Superconducting Tapes and wires (M.S. Thesis) LBL-4174, Dec. 1975 .

3. Z.J.J. Stekly, Jo of Applied Physics 42, 1 (Jan. 1971).

4. B. T. Matthias, T.H. Geballe, S. Geller and E. Corenzwit, Phys. Rev. Letters 6, 89 (1961).

5. J. E. Kunzler, E. Buehler, F.S.L.Hsu, and J. H. Wernick Phys. Rev. Letters 6, 89 (1961).

6. B. T. Matthias, T.H. Gebal1e, L. D. Longinotti, E. Corenzwit, G. W. Hull, R. H. Willens, J. P. Maita, Science 156, 645 (1967).

7. L. D. Hartsough, V. F. Zackay and E. R. Parker, Appl. Phys Lett. 132,68 (1968)。

8. D. P. Modi, Experimental Investigation of Densification of Powdered A15 phase in the System Nb-Al-Ge (M.S. Thesis), LBL 4173, Feb. 1976.

9. R. Lohberg, T.W. Eagar, I. M. Puffer, and R. M. Rose, App1. Phys。 Lett. 22, No. 2, 69 (Jan. 1973)。

10. J.A. Cave, T. J. Davies and F. C. Carpenter, J. of Less Common Metals, 42, 335-344 (1975)。

11. Kanithi Hemachalam, Filamentary Niobium-Tin Superconductors Fabricated by a Powdex Metallurgy Approach, (D. Eng. Thesis) LBL-4181, February 1976.

12. Holthius, John T., Private communication. 
13. A. Miller, Z. Naturforsch 25A, 1659-69 (1970).

14. J. A. Cave and T. J. Davies, Metal Science 8, 28 (1974).

15. G. Arrhenius, E. Corenzwit, R. Fitzgerald, G. W. Hull, Jr。, H. L. Luo, B. T. Matthias and W. H. Zachariasen, U. C. San Diego, AF-AFOSR-631-67.

16. M.L. Pickesimer, United States Atomic Energy Commission, Oak Ridge National Laboratory Report 2296 (1957).

17. J. Chabanne, Effect of the Microstructure on the Superconductive Properties of $\mathrm{Nb}_{3} \mathrm{Sn}$ in a $\mathrm{NbC}$ Matrix (M.S. Thesis), UCRL 17826 , September 1967.

18. T. N. Garret, Pulsed Magnetic Fields and the Critical Current Densities of Superconducting $\mathrm{Nb}_{3}$ Sn Stxips in these Fields (M.S. Thesis), LBL-448, December 1971.

19. U. Zwicker, H. J. Miericke and H. J. Renner, IEEE Trans. MAG-12, $28(1976)$.

20. E. Tanaka, T. Fukuda, and S. Kuma, App1. Phys. Lett. 14, 12, 389 (June 1969)。

21. J. Ruzicka, Cryogenics, 14, 434 (August 1974).

22. J. K. Hulm, J. R. Gavaler, M. A. Janoko, A. Patterson, C. K. Jones, 12th International Conference on Low Temp. Phys., Kyoto, Japan, $325,(1970)$.

23. R. H. Hammond, K. M. Ra11s, C. H. Meyer, D. P. Snowden, G. M. Kelly, J.H. Pereue, J. App1. Phys。43, 2407 (1972)。

24. S. Kobayashi, University of California, Berkeley, Private communication 
Table I. Materials Used

\begin{tabular}{|c|c|c|c|}
\hline Material & Source & $\begin{array}{l}\text { Nominal } \\
\text { Purity }\end{array}$ & Form \\
\hline A1 & Contronics Corporation & 99.9 & Powder $(-325)$ mesh \\
\hline A1 & United Mineral And Chemical & 99.999 & $7 / 8^{19} \operatorname{rod}$ \\
\hline $\mathrm{Ge}$ & Orion Chemical Company & 99.9999 & Powder $(-400)$ mesh \\
\hline $\mathrm{Ge}$ & United Mineral and Chemical & 99.99 & Solid Bars 5-20 ohm/cm. \\
\hline $\mathrm{Nb}$ & Teledyne, Wah Chang, Albany & 99.9 & Powder $\begin{aligned} & (-270+325), \\
& (-325+400) \text { mesh }\end{aligned}$ \\
\hline $\mathrm{Nb}$ & Fansteel Mfg. Company & 99.95 & $\begin{array}{c}\text { Tubes } 1 / 4^{\circ 9} \text { oD }\left(0.063^{\circ 1}\right) \\
\text { wall }\end{array}$ \\
\hline $\mathrm{Ta}$ & Fanstee1 Mfg. Company & 99.9 & $\begin{array}{c}\text { Tubes } 1 / 4^{\prime \prime} \text { oD }\left(0.020^{\prime \prime}\right) \\
\text { wa11 }\end{array}$ \\
\hline $\mathrm{Cu}$ & $\begin{array}{l}\text { American Brass and Copper } \\
\text { Co. }\end{array}$ & ASTM B75 & $\begin{array}{l}\text { Hard drawn tubes } \\
3 / 8^{\prime \prime},\left(0.065^{\prime \prime} \mathrm{W}\right) \\
1 / 4^{\prime \prime} \text { OD }\left(0.035^{\prime \prime} \mathrm{W}\right), \\
1 / 4^{\prime \prime} \text { OD }\left(0.065^{\prime \prime} \mathrm{W}\right)\end{array}$ \\
\hline
\end{tabular}


Table II. Diffusion heat treatments

\begin{tabular}{|c|c|c|}
\hline Temperature ${ }^{\circ} \mathrm{C}$ & Reaction Time & Sample Designation \\
\hline 1300 & $15 \mathrm{sec}$ & $1 \mathrm{~A}($ Fig, $20 a-b)$ \\
\hline 1300 & 1. min & $1 B$ \\
\hline 1300 & $21 / 2 \min$ & 1C (Fig. $18 a-b)$ \\
\hline 1300 & $15 \mathrm{sec}+\mathrm{HT} 750^{\circ} 96 \mathrm{hrs}$ & $1 D$ \\
\hline 1400 & $1 \min$ & $2 B$ \\
\hline 1550 & $15 \mathrm{sec}$ & $3 A$ \\
\hline 1550 & $1 \min$ & $3 B$ \\
\hline 1550 & $21 / 2 \mathrm{~min}$ & $3 \mathrm{C}$ \\
\hline 1660 & $15 \mathrm{sec}$ & $4 \mathrm{~A}$ \\
\hline 1750 & $15 \mathrm{sec}$ & $5 A$ (Fig. $19 a-b)$ \\
\hline 1750 & $1 \mathrm{~min}$ & $5 B$ \\
\hline 1750 & $21 / 2 \min$ & 5C (Fig. $17 \mathrm{a}-\mathrm{b})$ \\
\hline
\end{tabular}


Table III. Critical Current Data $\left(\times 10^{4} \mathrm{amp} / \mathrm{cm}^{2}\right)$

\begin{tabular}{|c|c|c|c|}
\hline \multirow[t]{2}{*}{ Method } & \multicolumn{3}{|c|}{ Fields } \\
\hline & $20 \mathrm{kG}$. & $50 \mathrm{kG}$. & $60 \mathrm{kG}$ \\
\hline Infiltration $\left(J_{C}\right.$ considering A15\%) & 8.8 & 4.1 & 3.6 \\
\hline Infiltration (Overall $\mathrm{J}_{\mathrm{C}}$ ) & 1.8 & 0.88 & 0.78 \\
\hline Bulk samples, Ruzicka ${ }^{21}$ & 1.2 & 0.5 & 0.4 \\
\hline Bulk samples, Hartsough ${ }^{7}$ & 0.5 & 0.2 & 0.15 \\
\hline $\begin{array}{l}\text { Ribbons prepared by swaging } \\
\text { and rolling, Lohberg, }\end{array}$ & 0.84 & 0.16 & 0.15 \\
\hline Evaporated thin films ${ }^{23}$ & 60 & 40 & $-\infty$ \\
\hline
\end{tabular}


FIGURE CAPTIONS

Fig. 1. Equilibrium Phase Diagxam of Al-Ge.

Fig. 2. Al-Ge eutectic microstructures; (a) Made out of A1 and Ge powders, (b) Made out of solid A1-Ge and slow cooled from $600^{\circ} \mathrm{C}$. (c) Slow cooled from $700^{\circ} \mathrm{C}$, (d) Quenched from $700^{\circ} \mathrm{C}$.

Fig. 3. Al-Ge eutectic a1loy as cast (a) Microstructure and Vickers hardness indentation (b) Composition display.

Fig. 4. Effect of the microstructure changes with heat treatments in Al-Ge eutectic. Vickexs hardness indentations are shown:

(a) slow cooled from $700^{\circ} \mathrm{C}$, (b) Quenched from $700^{\circ} \mathrm{C}$, (c) slow cooled from $600^{\circ} \mathrm{C}$, (d) Quenched from $600^{\circ} \mathrm{C}$.

Fig. 5. Effect of the microstructure and hardness changes with heat treatment in $\mathrm{Al}-\mathrm{Ge}$ eutectic. (a) Slow cooled from $500^{\circ} \mathrm{C}$, (b) Quenched from $500^{\circ} \mathrm{C}$, (c) Slow cooled from $400^{\circ} \mathrm{C}$, (d) Quenched from $400^{\circ} \mathrm{C}$.

Fig. 6. Vickers microhardness of Al-Ge eutectic as a function of heat treating temperature.

Fig. 7. Schematic diagram of the several stages in multifilamentary superconductor manufacturing.

Fig. 8. Schematic Diagram of Abar furnace; 11 1. extension tube, 2. tantalum rod, 3. back filling port, 4. electrical leads, 5. heating element, 6. niobium specimen, 7. radiation shields 8. water cooled wall, 9 . W-5\% Re vs $W-26 \%$ Re thermocouple junction, 10. vacuum connection, 11. quartz tube, 12. graphite crucible, 13. 1iquid Al-Ge eutectic alloy and 14. resistance heater. 
Fig. 9. Sintered Nb powder $(-325+400$ mesh); (a) Particle bond, (b) Interconnected pores. Both sintered at $2250^{\circ} \mathrm{C}-15 \mathrm{~min}$.

Fig. 10. Porous $\mathrm{Nb}$ rod infiltrated with $\mathrm{Al}$-Ge alloy; (a) Infiltrated at $700^{\circ} \mathrm{C}$, for 1 min., $1-3 \%$ excess $\mathrm{Al}$, (b) Infiltrated at $500^{\circ} \mathrm{C}$ for $21 / 2 \min$.

Fig. 11. Porous $\mathrm{Nb}$ rod infiltrated with $\mathrm{Al}-\mathrm{Ge}$ alloy; (a) At $700^{\circ} \mathrm{C}$, 1 min., $-325+400$ mesh $\mathrm{Nb}$ powder used. (b) At $500^{\circ} \mathrm{C}$, $21 / 2$ min., $-270+325$ mesh $\mathrm{Nb}$ powder used.

Fig. 12. (a) Form rolling machine, (b) $0.022^{\prime \prime} \times 0.022^{\prime \prime}$ form rolled sample, unreacted filaments.

Fig. 13. Form rolled samples; (a-b) $0.025^{\circ 1} \times 0.025^{\prime \prime}$ form rolled with $\mathrm{Nb}$ and hard drawn copper (Cu etched), (c-d) $0.022^{p 1} \times 0.022^{\prime \prime}$ form rolled with outer sheath of hard drawn copper only (Cu etched).

Fig. 14. Nb-Al-Ge phase diagram at $1840^{\circ} \mathrm{C}{ }^{13}$

Fig. 15. Scanning electron micrograph of an infiltrated, reacted, nondeformed sample. (A) Reaction at $1700^{\circ} \mathrm{C} 1 \mathrm{~min}$;

(B) Germanium rich phase, $\mathrm{Nb}_{5}(\mathrm{AI} G)_{3},(1) ;(\mathrm{C})$ o phase $\mathrm{Nb}_{2}(\mathrm{Al}$ Ge) Aluminum rich (2); (D) Al5 phase (3); (E) Nb solid solution with $A 1$ and Ce, (4).

Fig. 16. Scanning Electron Micrograph of a deformed and reacted sample.

(A) Filaments and relative concentration scan for Al and Ge;

(B) $\mathrm{Nb}_{5}\left(\mathrm{Al}(\mathrm{Je})_{3}(1) ; \quad\right.$ (C) A15 phase (2); (D) Nb solid solution( 3 ) 
Fig. 17. Sample form rolled to $0.022^{\prime \prime} \times 0.022^{\prime \prime}$, and reacted at $1750^{\circ} \mathrm{C}$ for $21 / 2$ minutes. (a) Iongitudinal section; 1 . Ge rich phase, $\mathrm{Nb}_{5}(\mathrm{Al} \mathrm{Ge})_{3} ; 2 . \mathrm{Nb}_{2}(\mathrm{Al} \mathrm{Ge}) ; 3 . \mathrm{A} 15$ phase, $\mathrm{Nb}_{3}(\mathrm{Al} \mathrm{Ge})$;

4. Niobium matrix; (b) cross section.

Fig. 18. Sample form rolled to $0.022^{\prime \prime} \times 0.022^{\prime \prime}$, reacted at $1300^{\circ} \mathrm{C}$ for 2 1/2 minutes (a) longitudinal section: 1. Ge rich phase, $\mathrm{Nb}_{5}(\mathrm{Al} \mathrm{Ge})_{3} ; 2 . \mathrm{Nb}_{2}(\mathrm{Al} \mathrm{Ge}) ; 3 . \mathrm{A} 15$ phase, $\mathrm{Nb}_{3}(\mathrm{Al} \mathrm{Ge})$; 4. Niobium matrix; (b) cross section.

Fig. 19. Sample form rolled to $0.022^{\prime \prime} \times 0.022^{\prime \prime}$ and reacted at $1750^{\circ} \mathrm{C}$ for 15 seconds. (a) 1ongitudinal section: 1. Ge rich phase, $\mathrm{Nb}_{5}(\mathrm{Al} \mathrm{Ge})_{3} ; 2$. $\mathrm{Nb}_{2}(\mathrm{Al} \mathrm{Ge}) ; 3$. A15 phase, $\mathrm{Nb}_{3}(\mathrm{Al} \mathrm{Ge})$;

4. Niobium matrix; (b) cross section.

Fig. 20. Sample form rolled to $0.022^{\prime \prime} \times 0.022^{\prime \prime}$ and reacted at $1300^{\circ} \mathrm{C}$ for 15 seconds. (a) 1ongitudinal section: 1. Ge rich phase, $\mathrm{Nb}_{5}(\mathrm{Al} \mathrm{Ge})_{3} ; 2 . \mathrm{Nb}_{2}(\mathrm{Al} \mathrm{Ge}) ; 3 . \mathrm{A} 15$ phase, $\mathrm{Nb}_{3}(\mathrm{Al} \mathrm{Ge})$; 4. Niobium matrix; (b) cross section.

Fig. 21. Critical current evaluation; (a) Explanation of recordings and interpretation, (b) Typical oscilloscope display.

Fig. 22 Overall critical current density for samples heat treated at 15 seconds as a function of applied field and temperature.

Fig. 23 Overall critical current density for samples heat treated at 1 minute. $J_{C^{\circ}} v s . H$. at several temperatures.

Fig. 24. Overall critical current density for samples heat treated at $21 / 2$ minutes. $J_{C}$, vs $H_{0}$ at several temperatures. 
Fig. 25. True critica1 current density considering the A15 fraction for samples heat treated at $1300^{\circ} \mathrm{C}$ and $1750^{\circ} \mathrm{C}$.

Fig. 26. Dependence of transition temperature on reaction temperature. 


\section{Al-Ge Aluminum-Germanium}

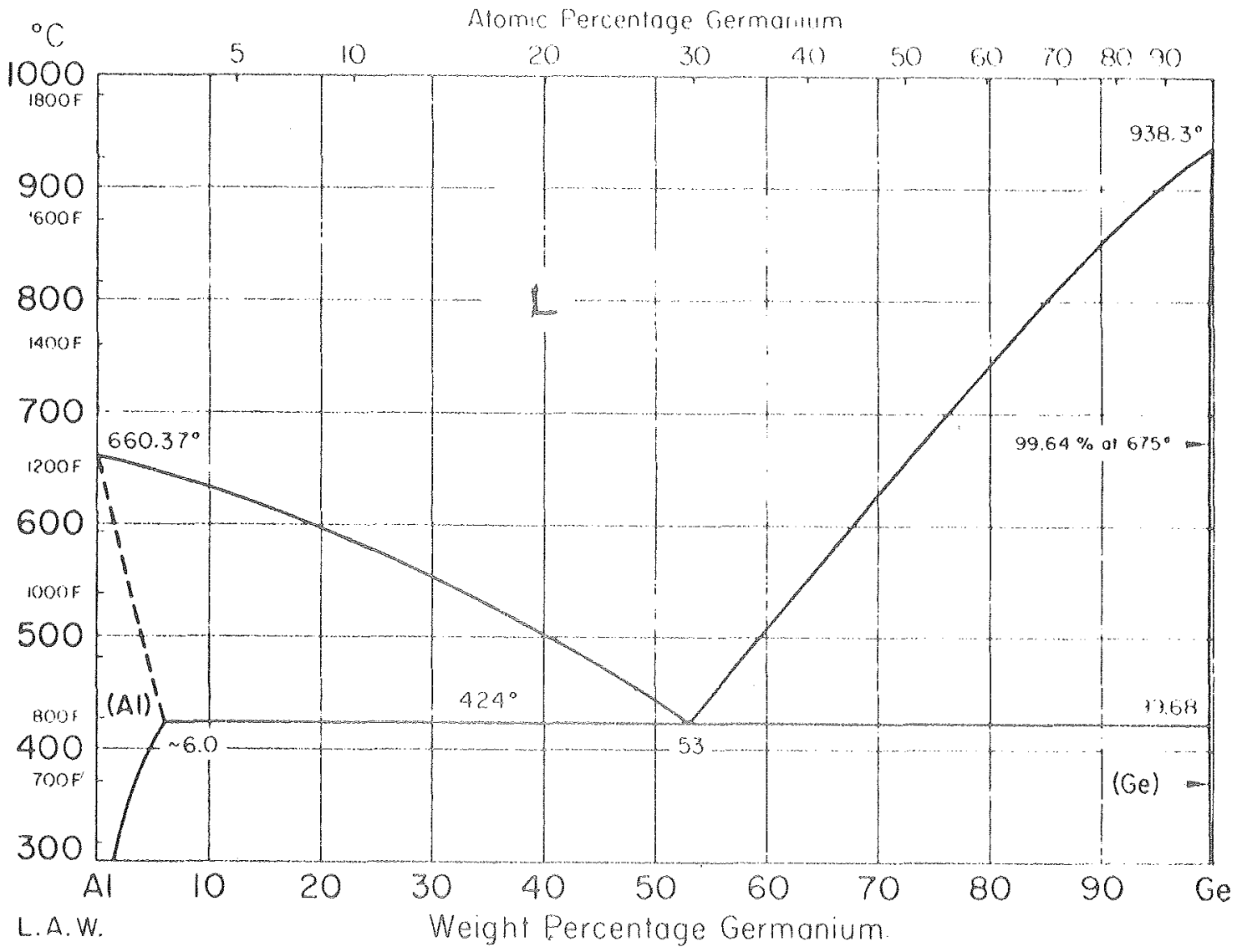

XBL 7678550

Fig. 1 
$09004 \times 03732$

$-39$.
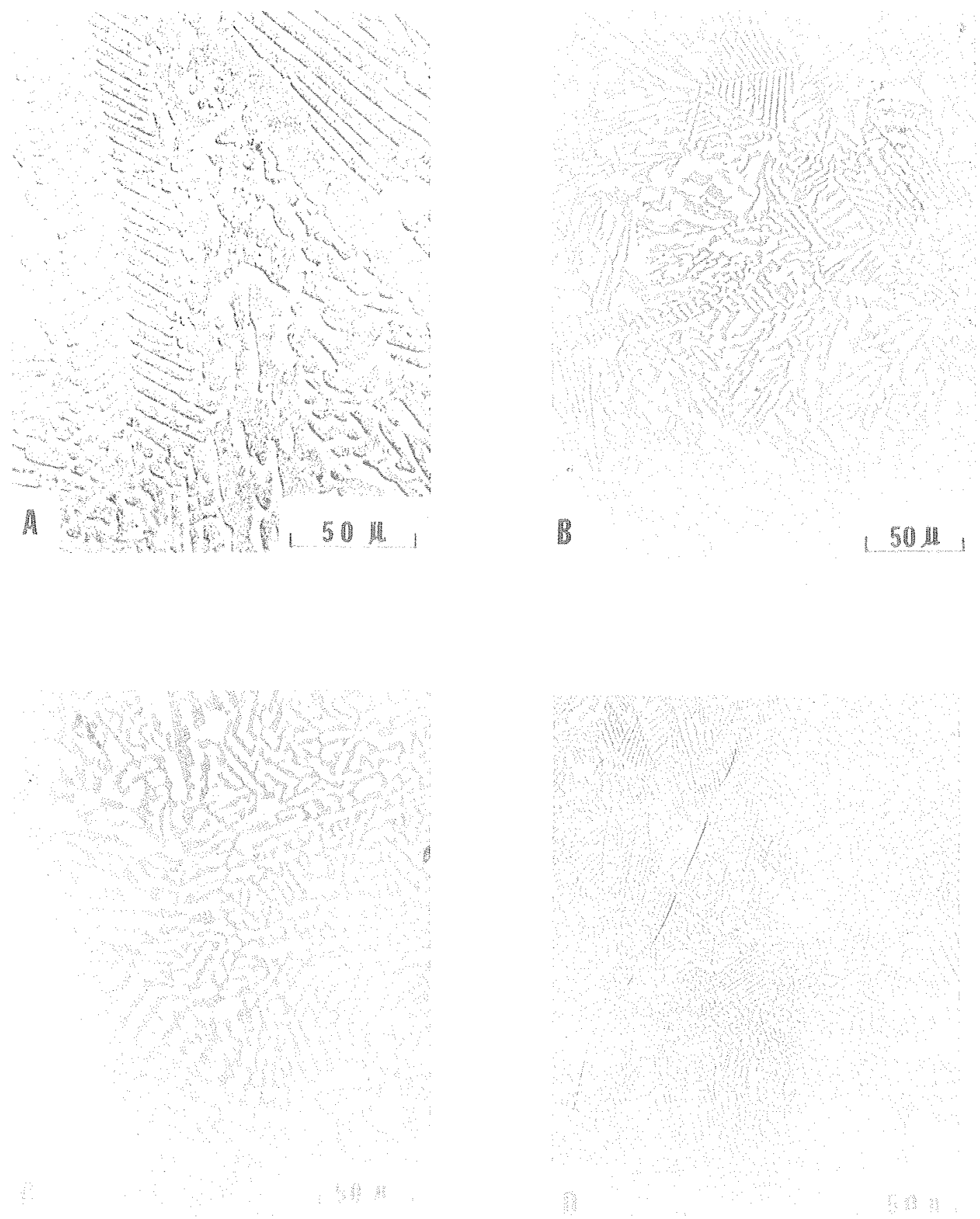

XBB $768-7501$

lig. 2 


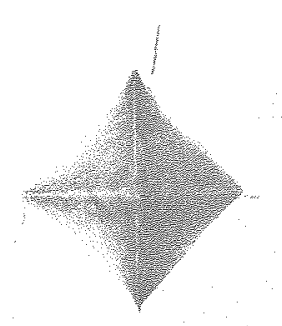

ำ

5011

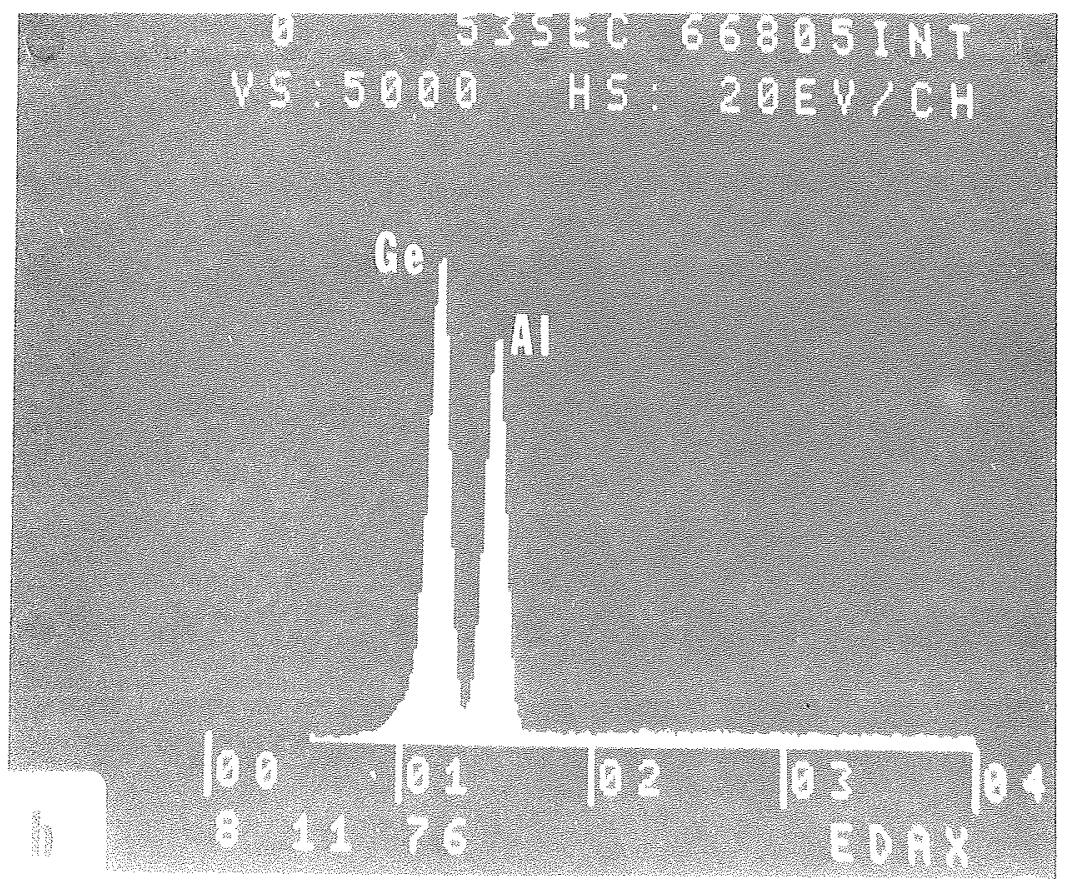

XB! $768-7570$

Iis. 3 

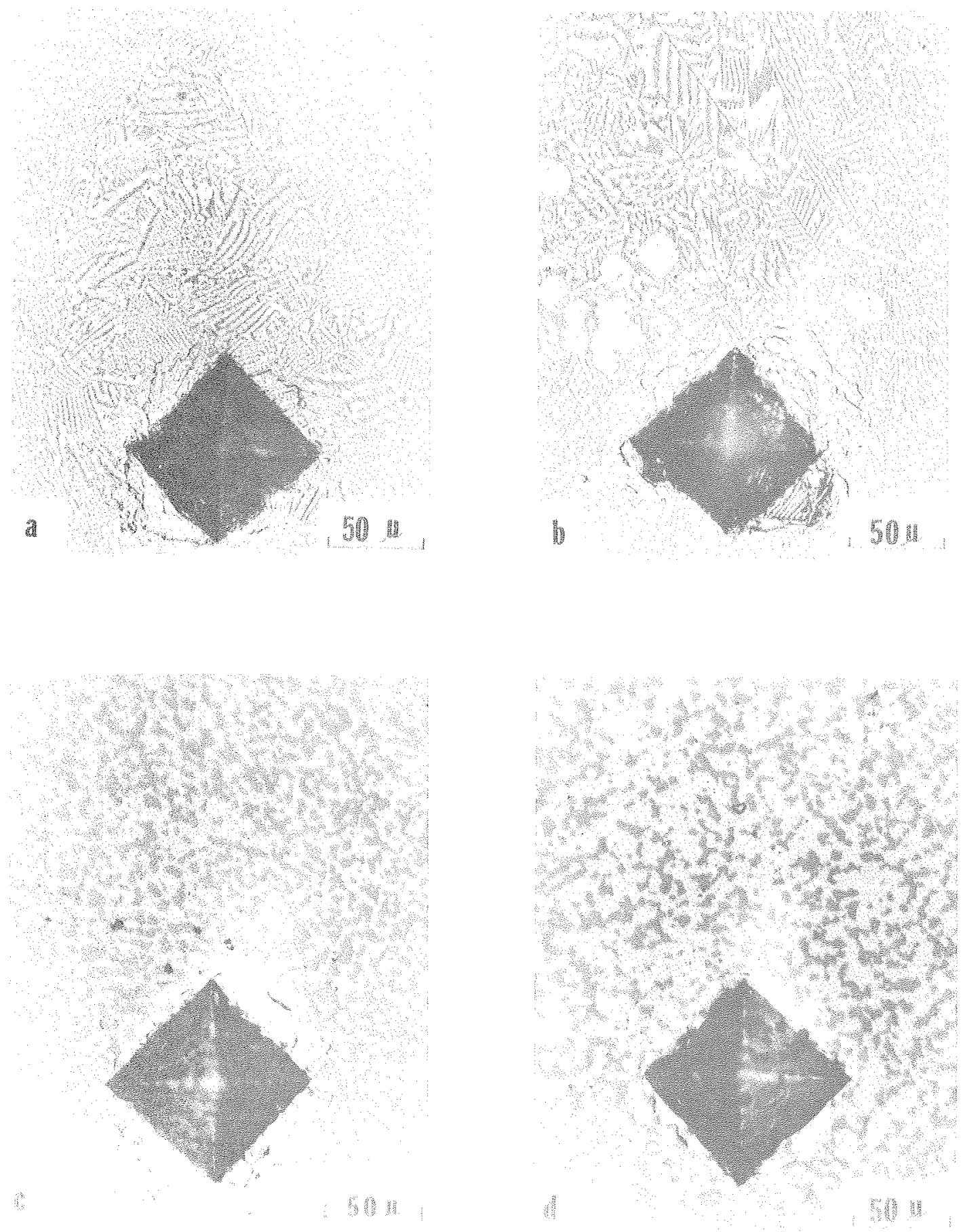

XBB $708-7559$ 


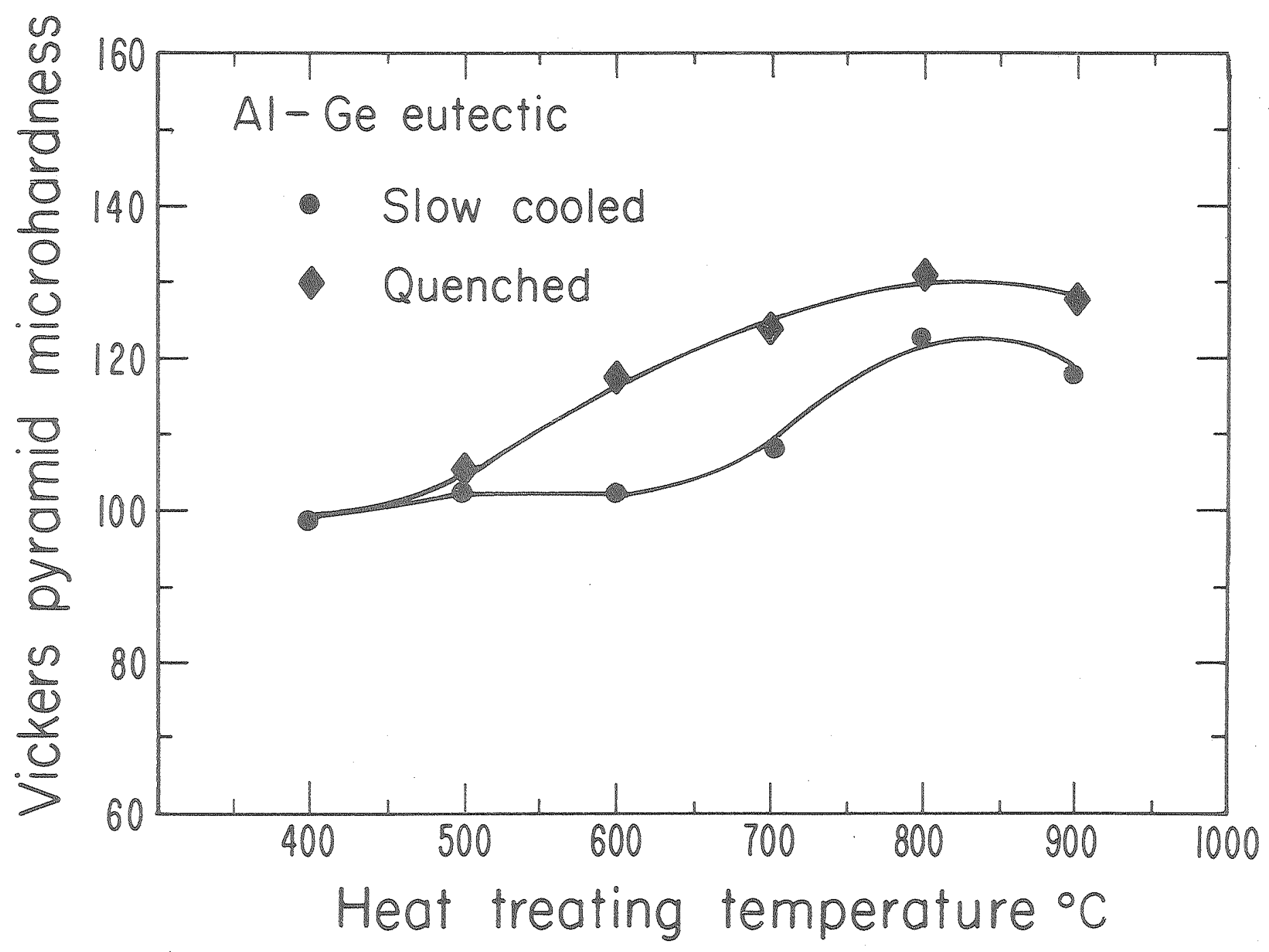




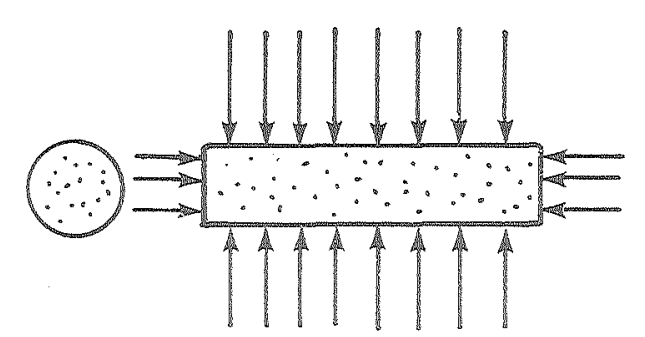

a) Isostatic compaction of $\mathrm{Nb}$ powder

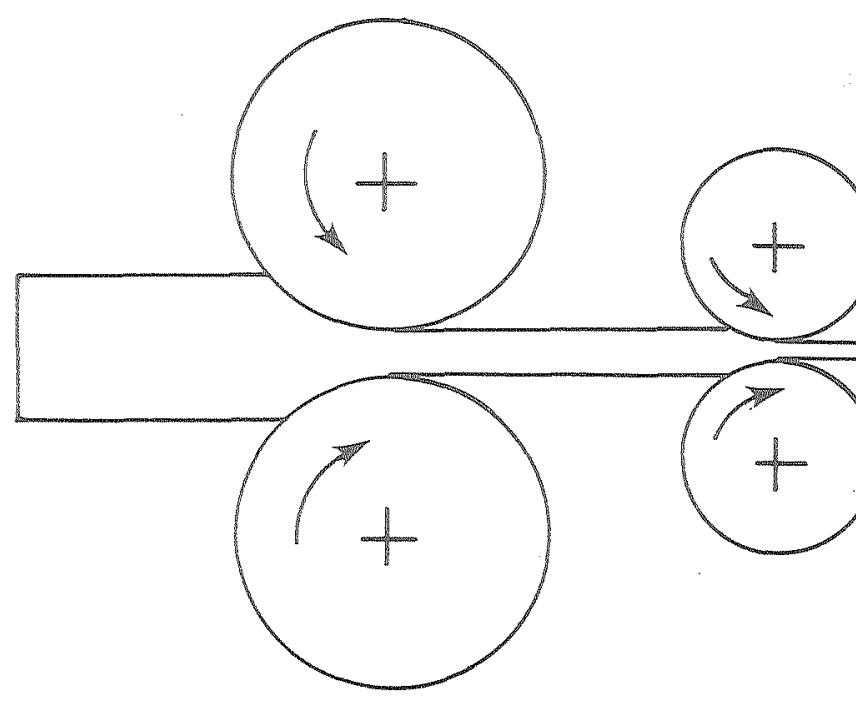

d) Mechanical deformation

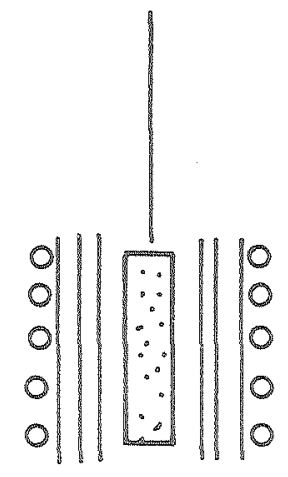

b) Sintering

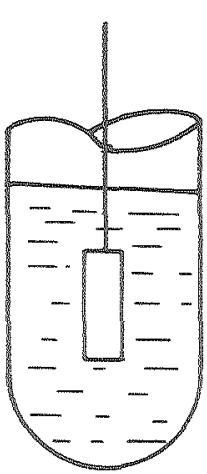

c) Infiltration with Al-Ge 


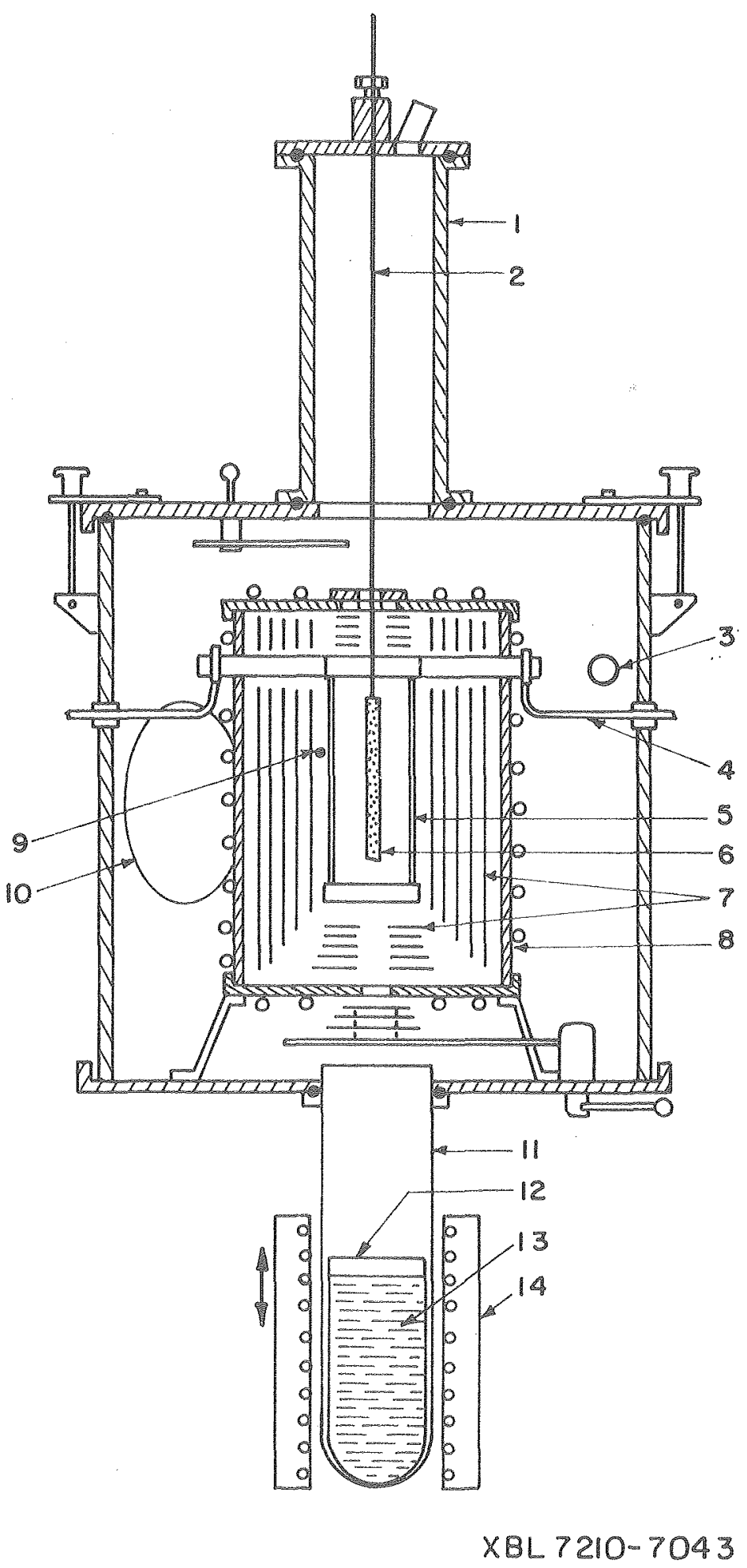

Fig. 8 

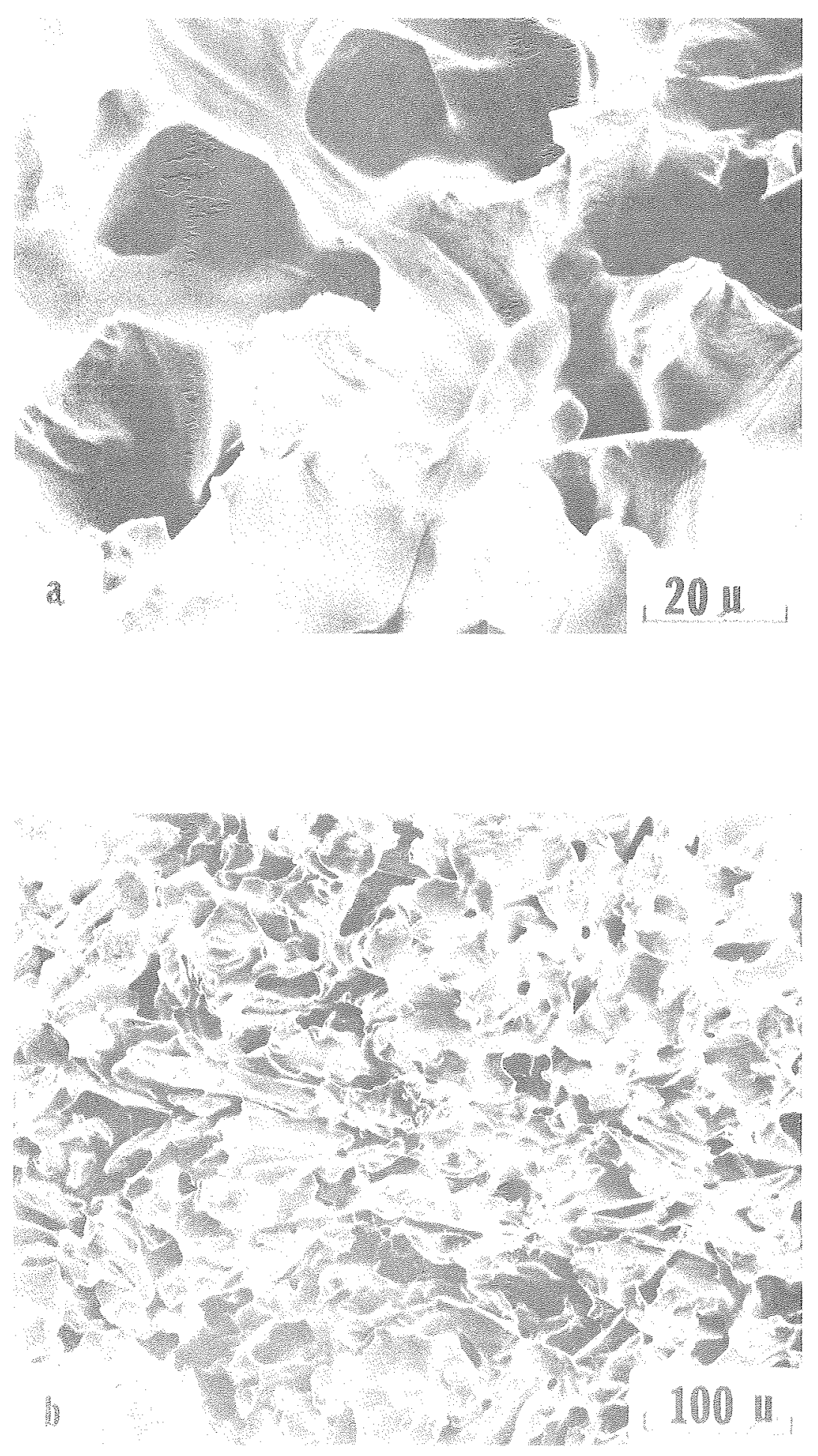

XBB $768-7503$

1is. 9 

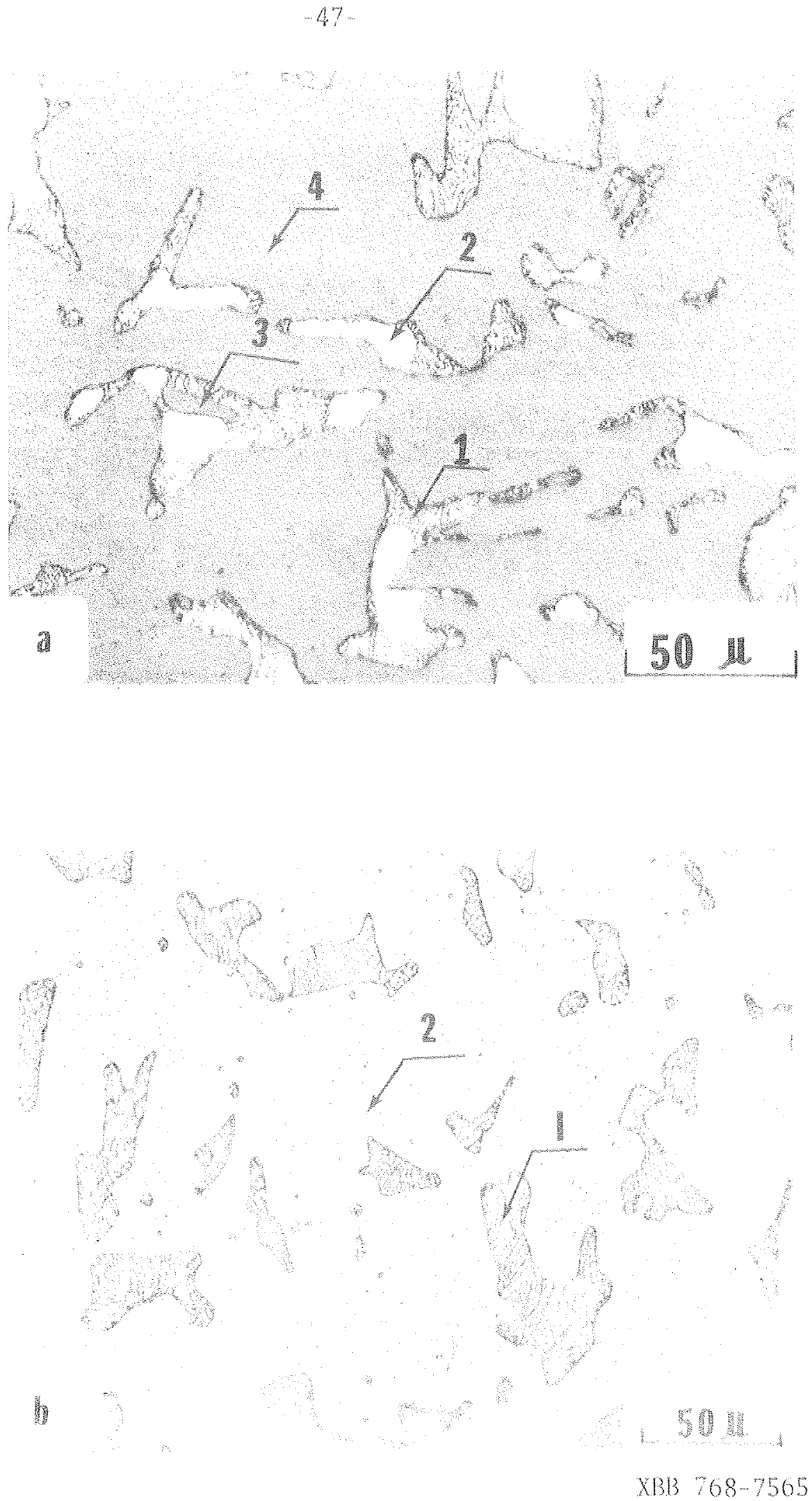

lig. 10 

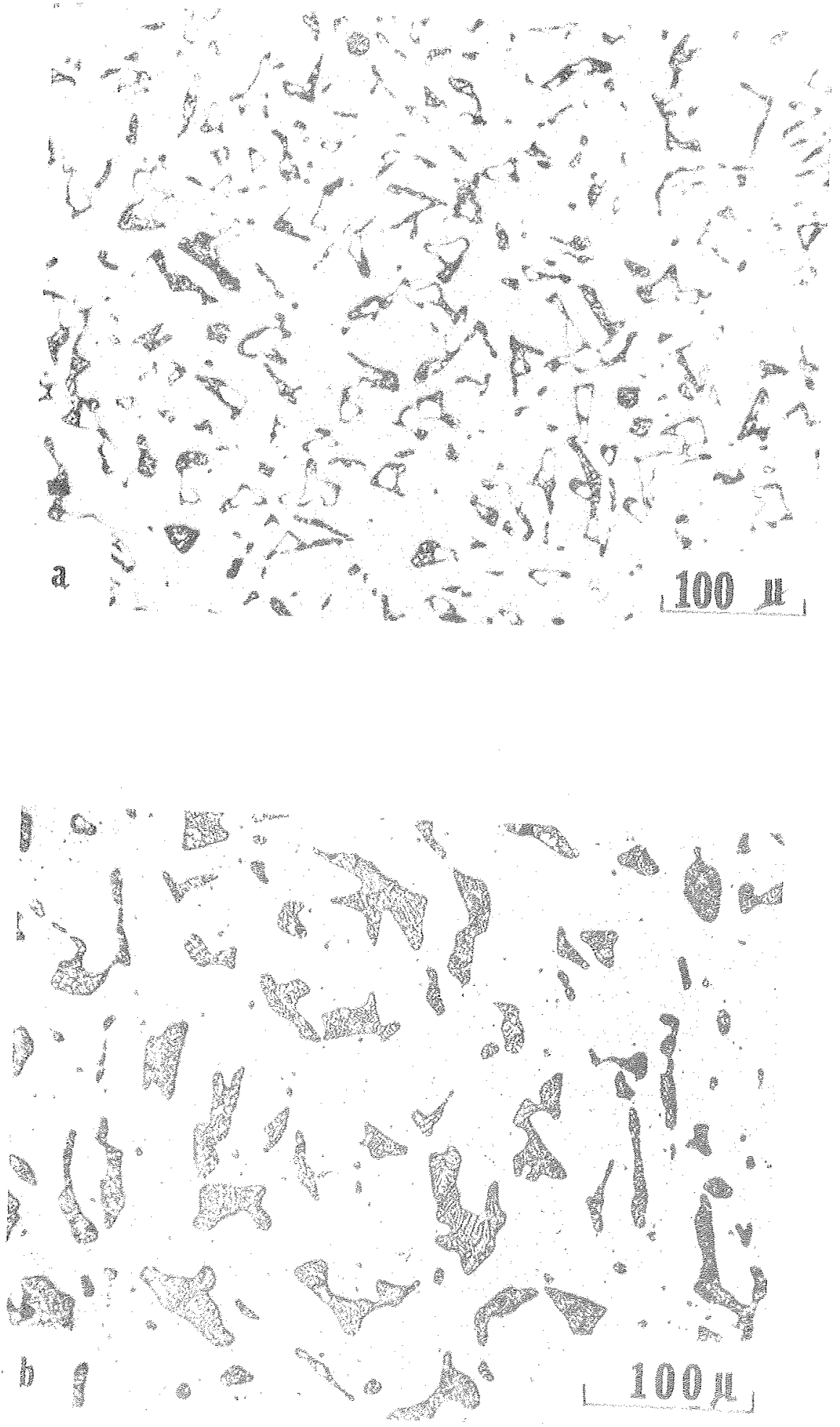

XBB $768-7564$

$\operatorname{lig}=11$ 
d 30 or

$-49$
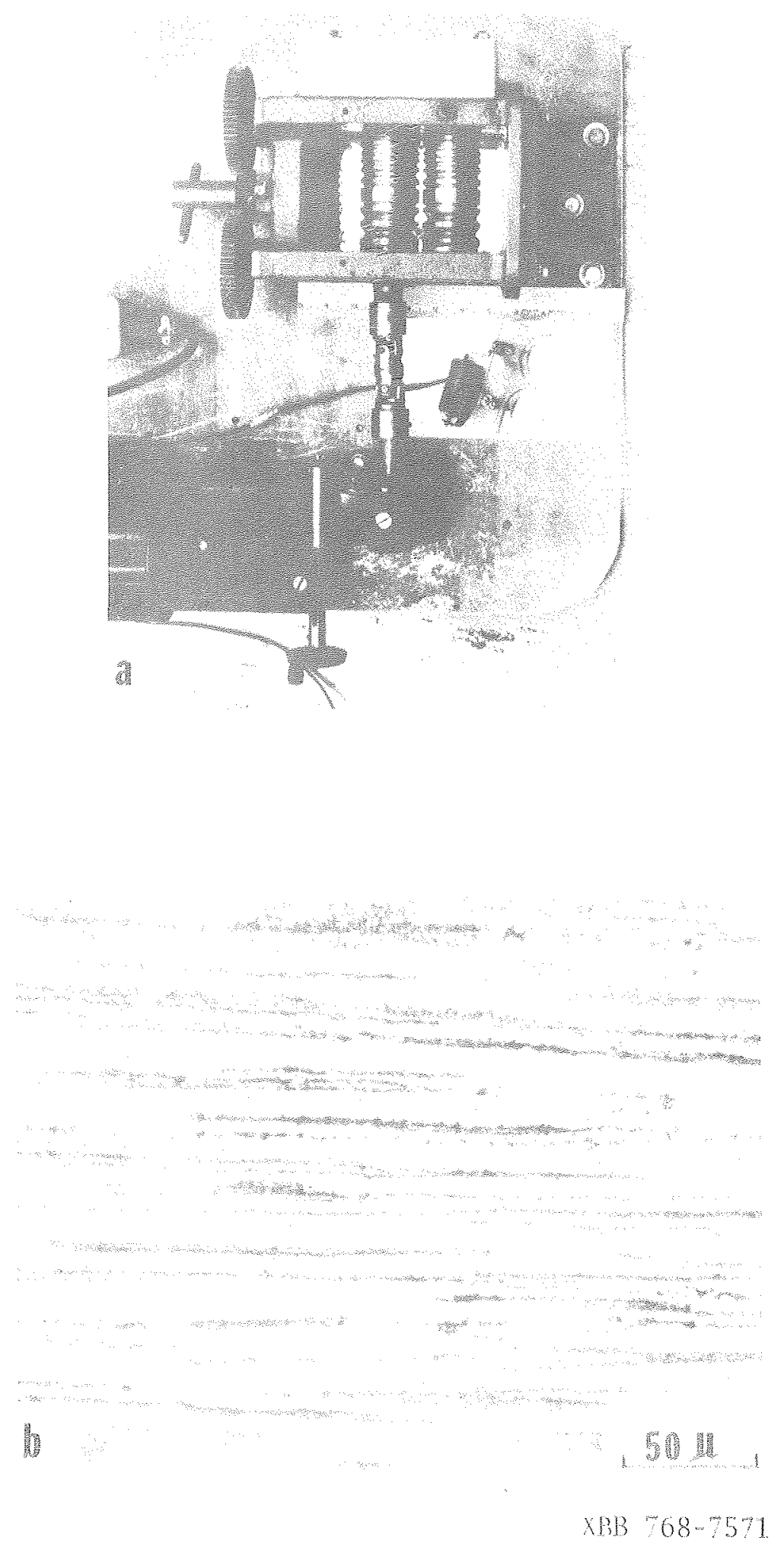

Hio. 12 

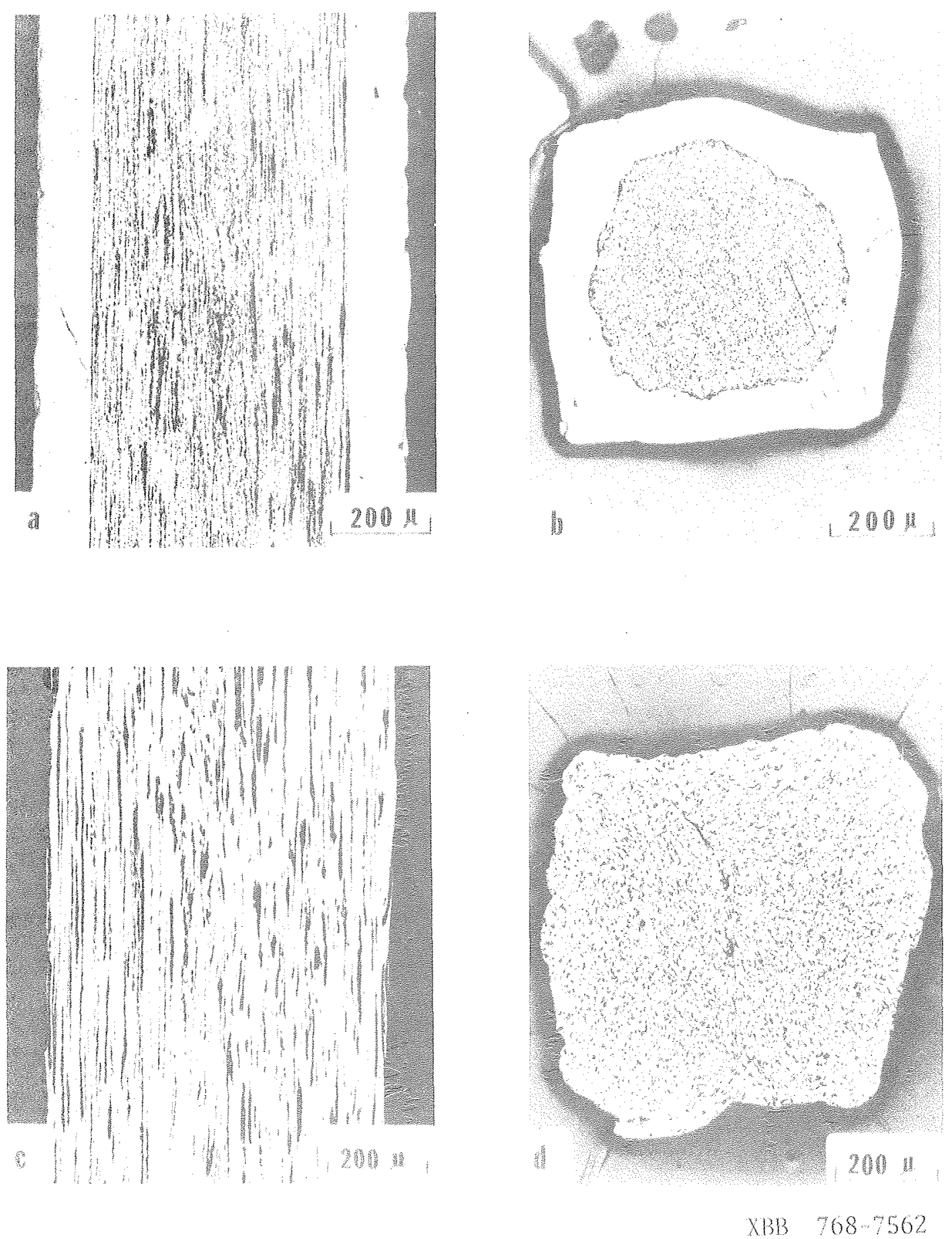

lig. 13 


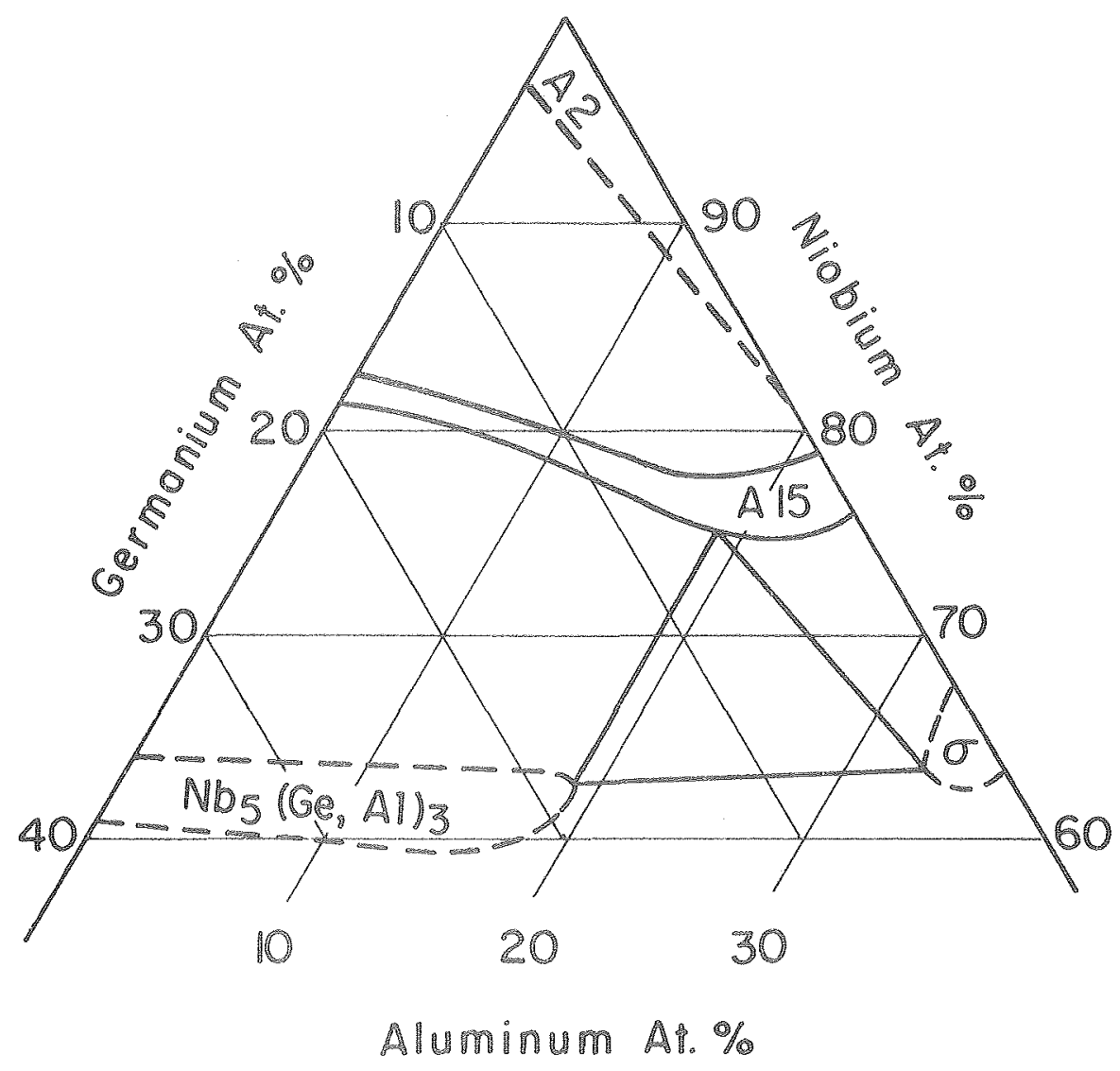

XBL $761-6346$

Fig. 14 

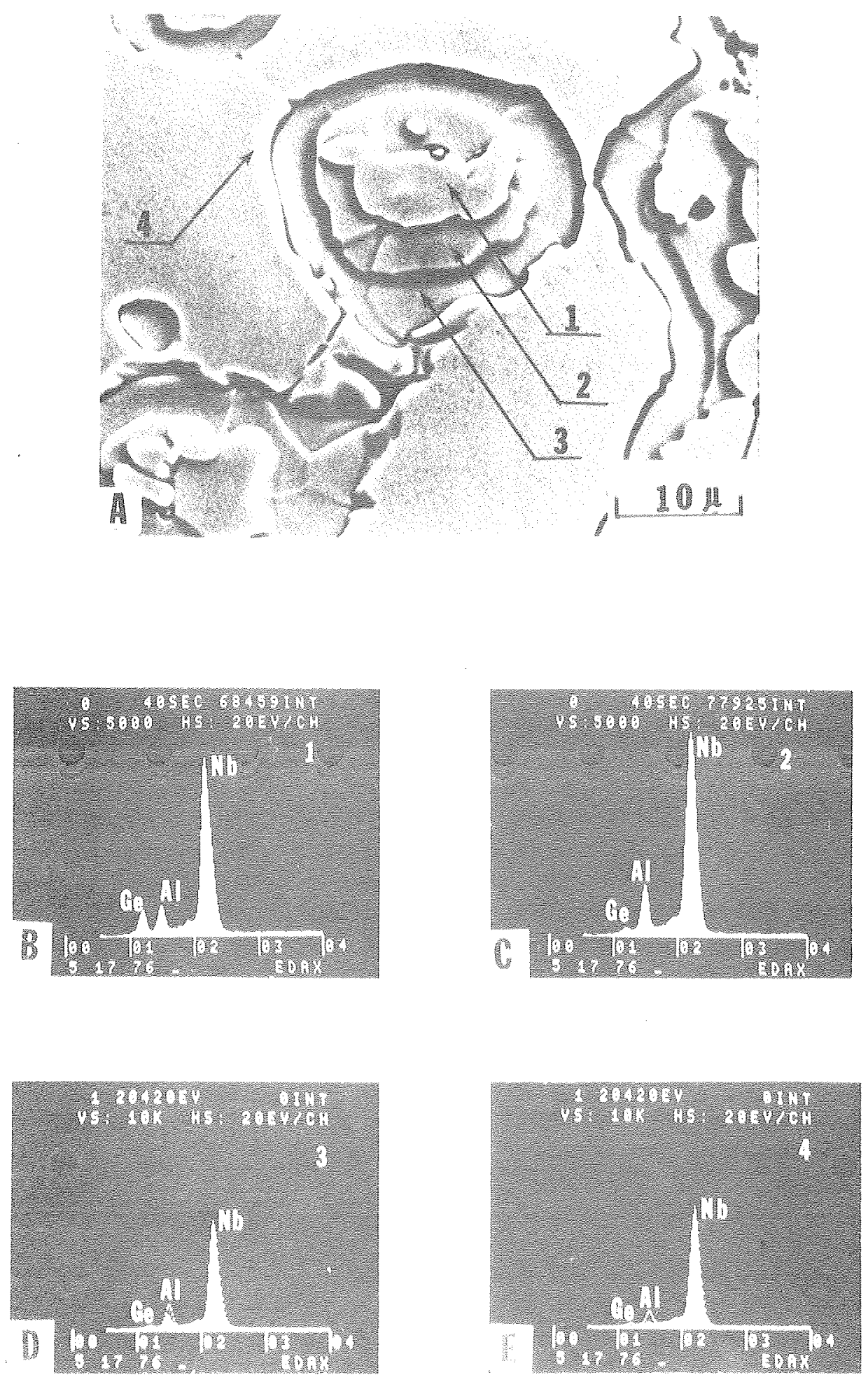

XBB $\quad 08-7289$ 

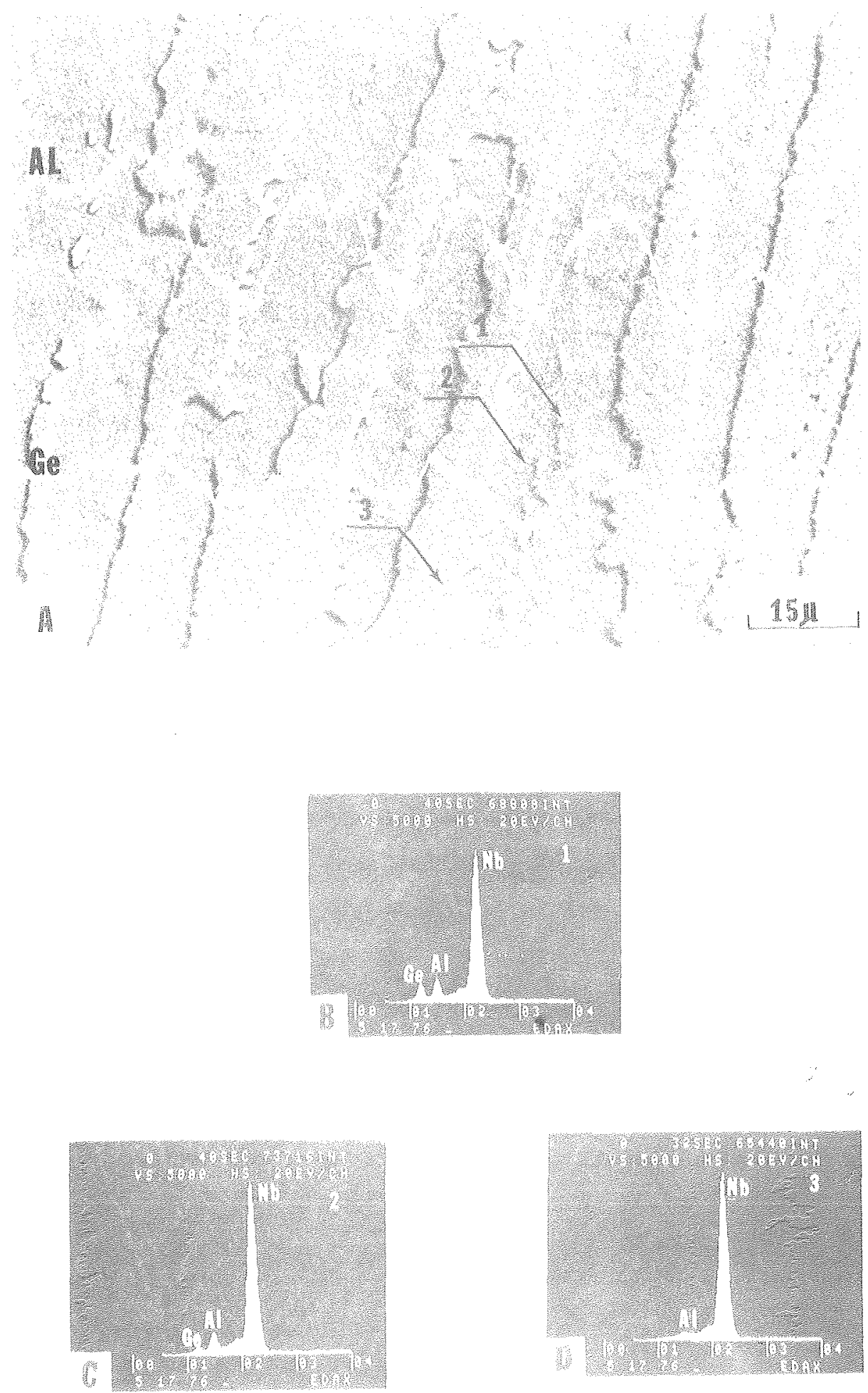

XBB $\quad 08-7200$ 

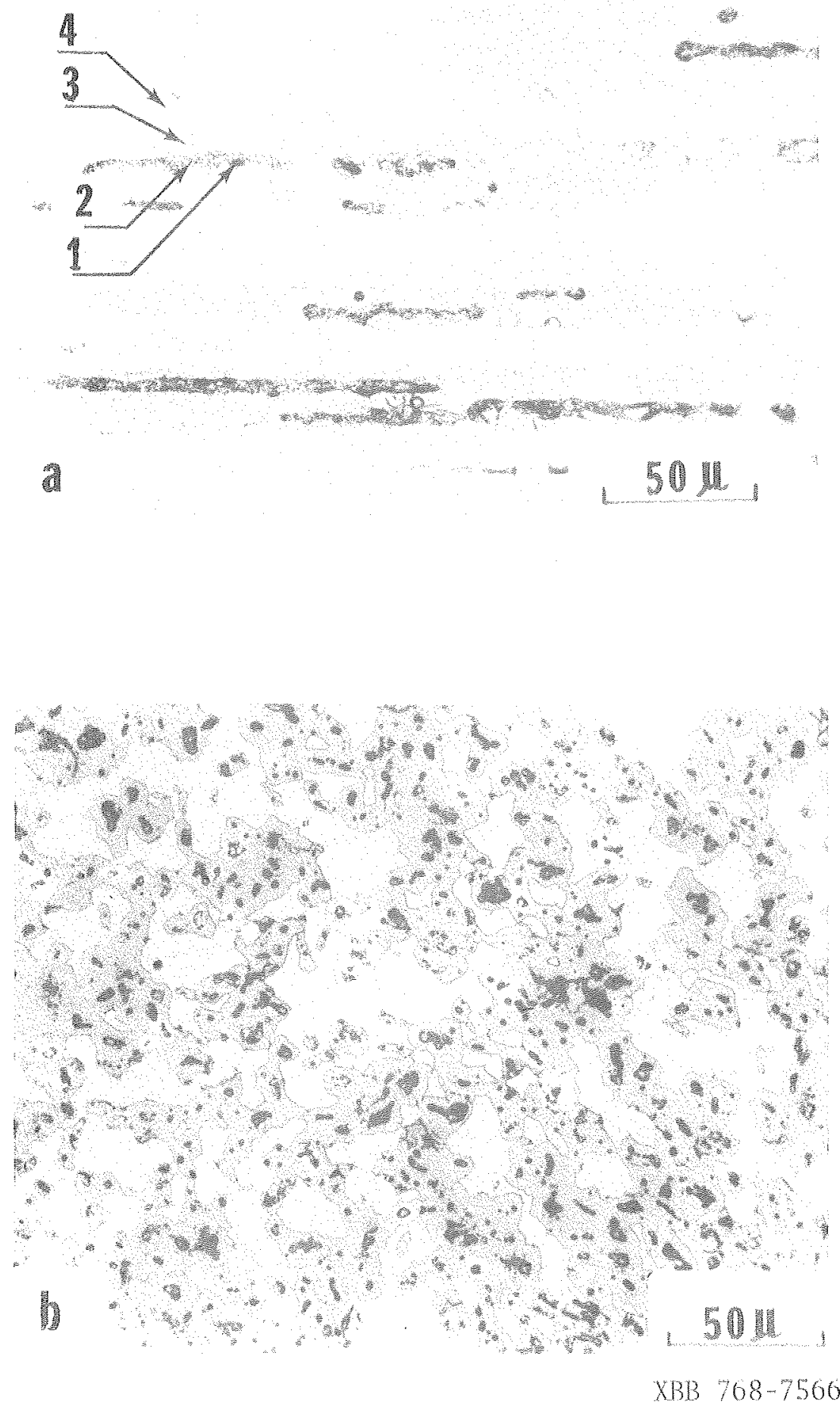

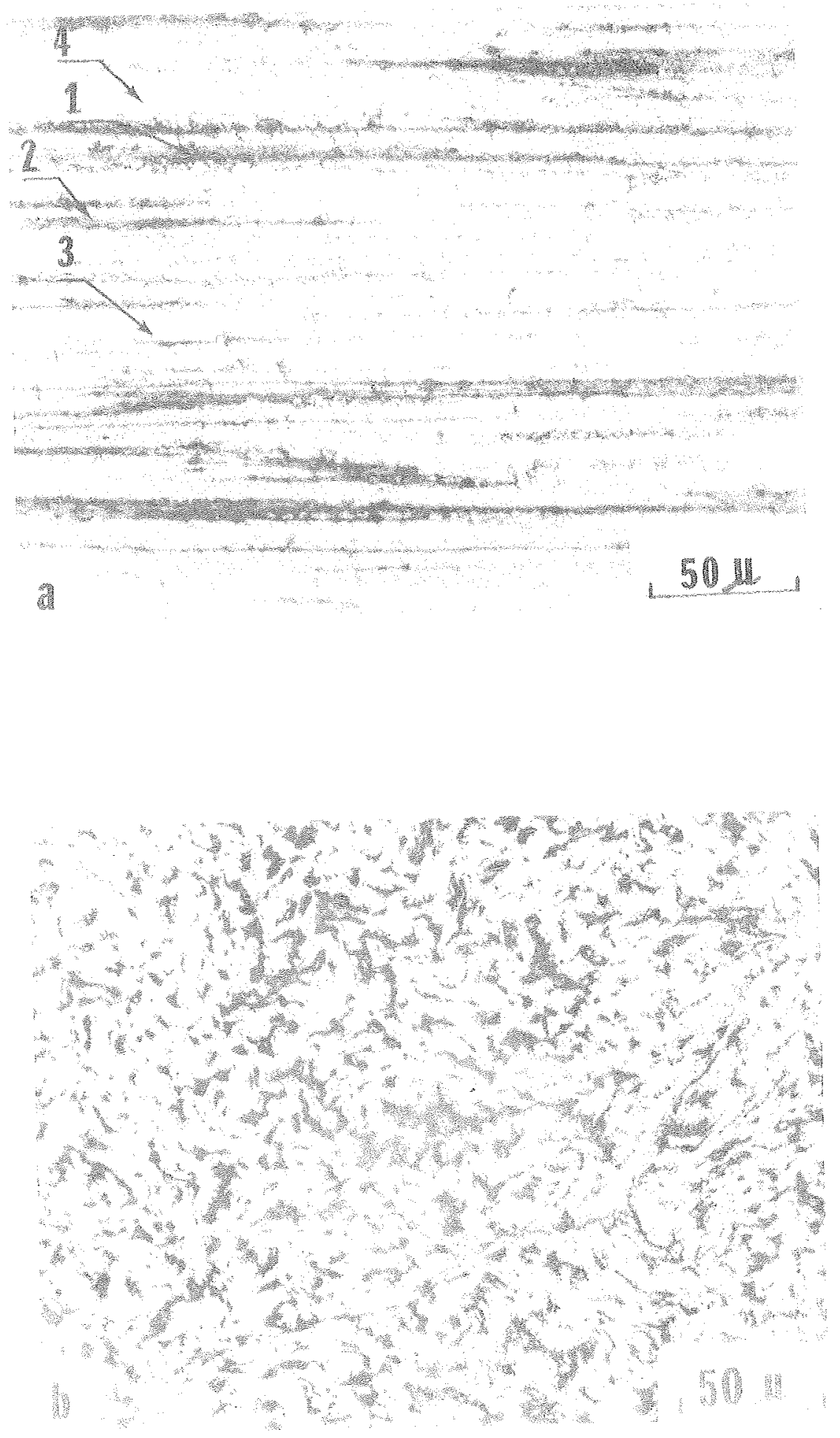

XBB $708 \% 56$ 

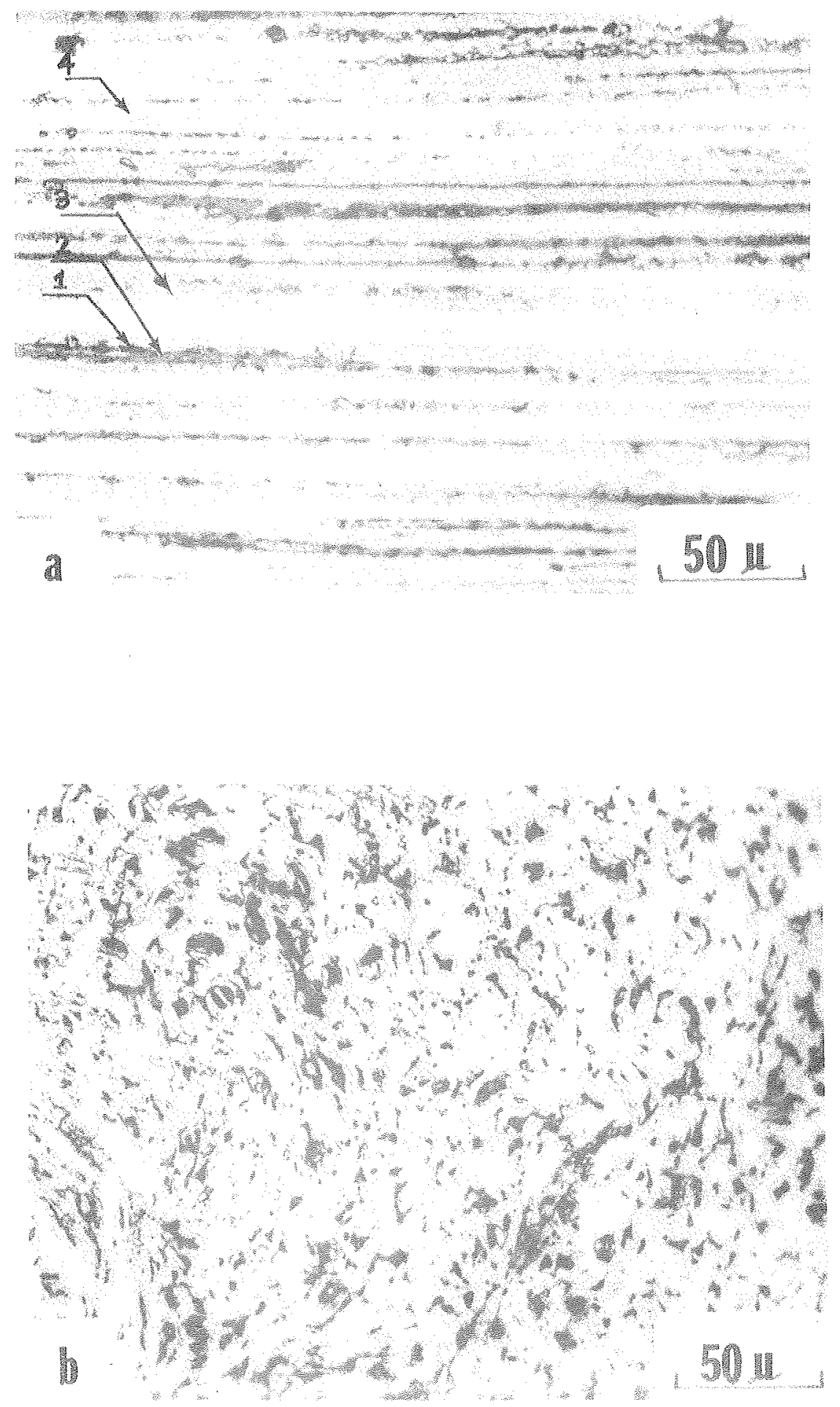

XBB $768-7568$ 
$-58-$

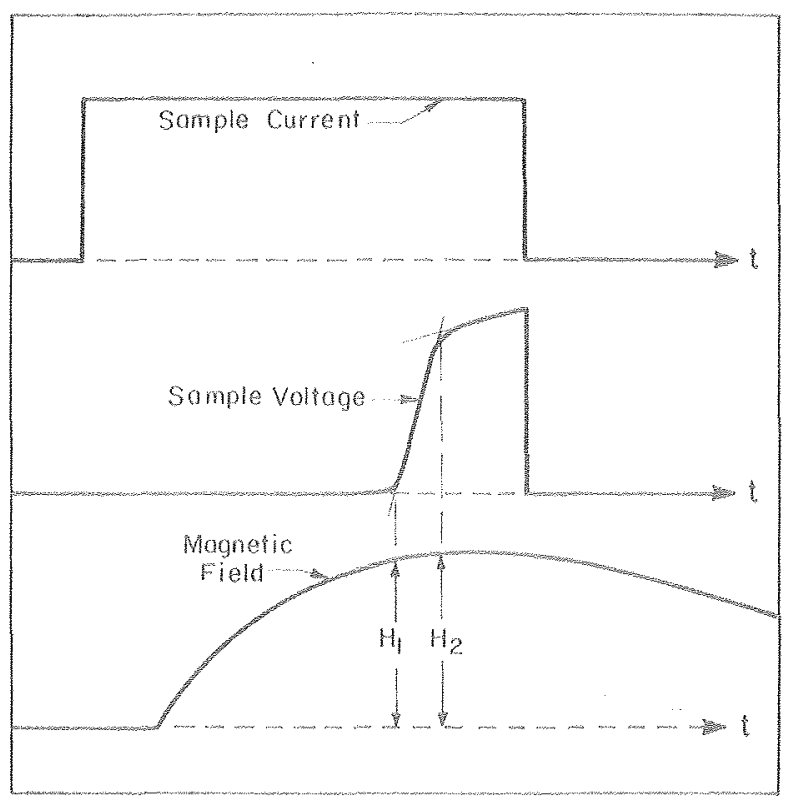

留

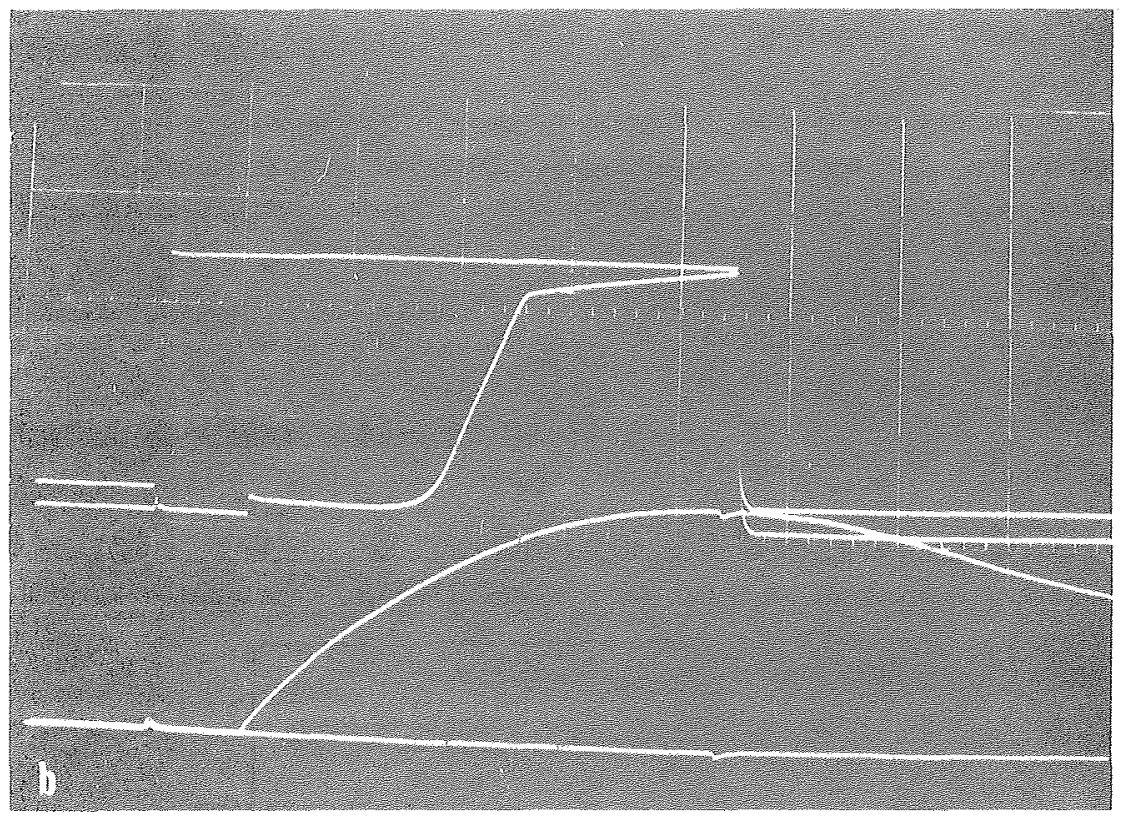

X $3 B \quad 768-7558$

Fis. 21 
N

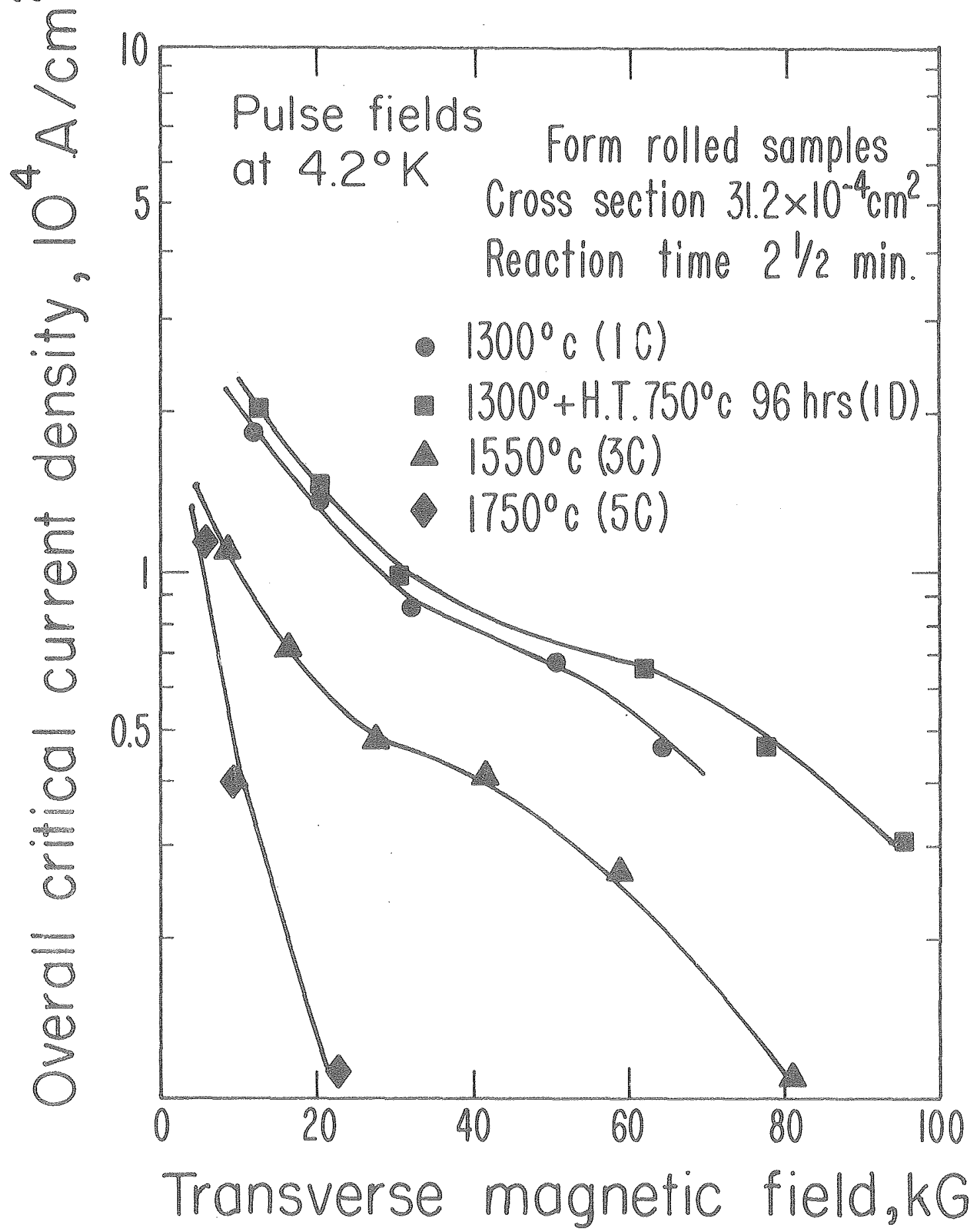

XBL $768 \quad 3364$

Fig. 22 


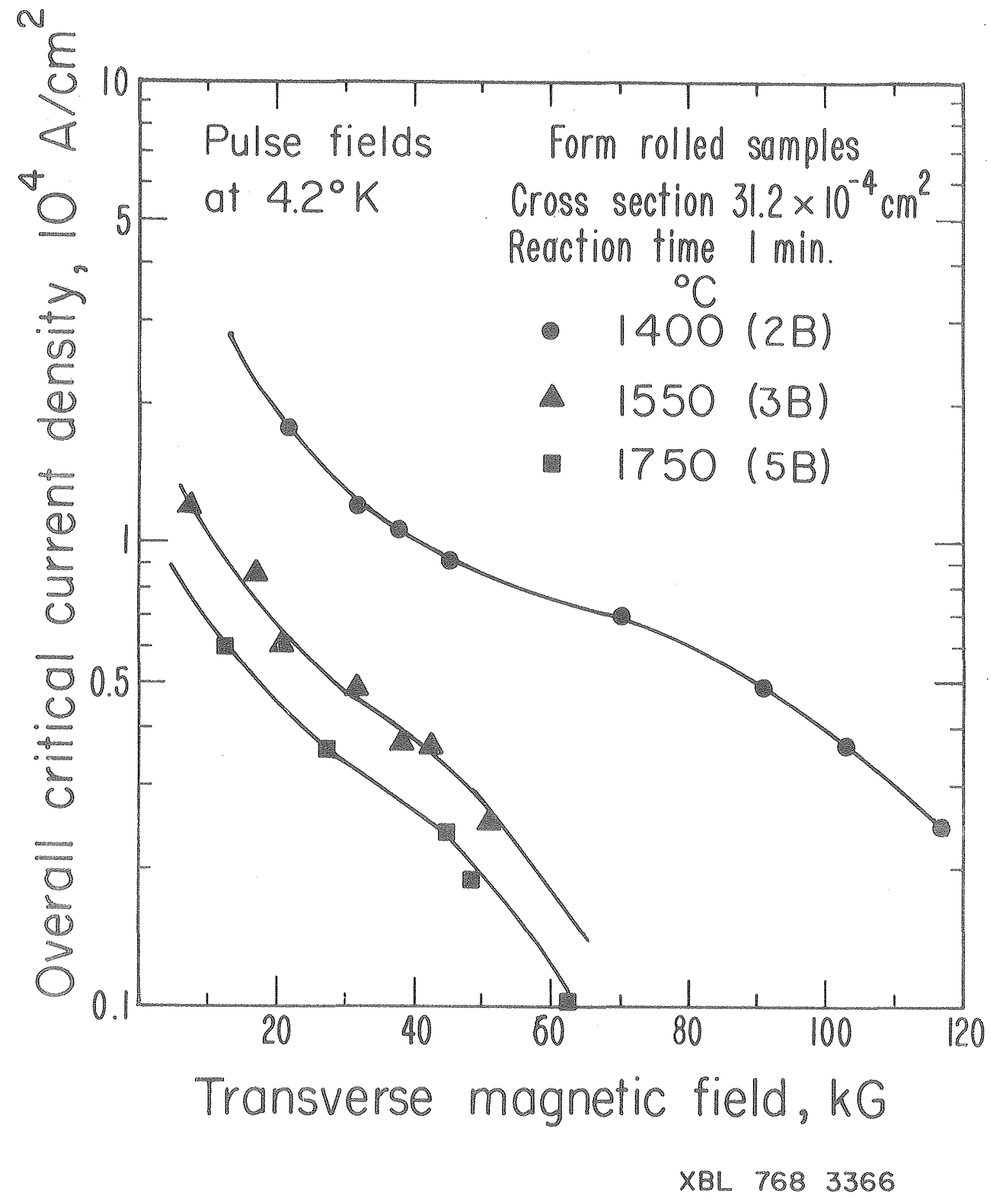

lig. 23 


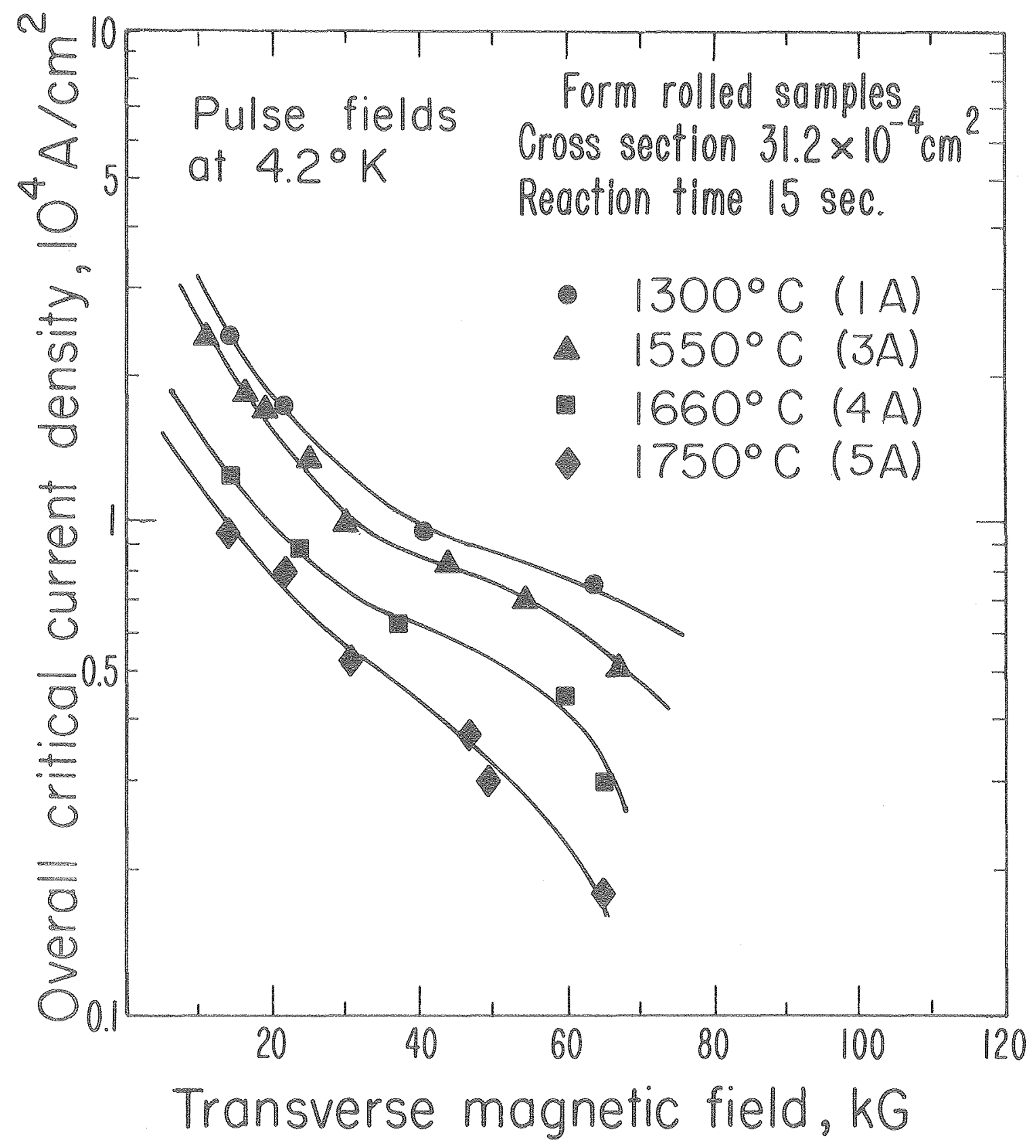

XBL $768 \quad 3368$

Fig. 24 


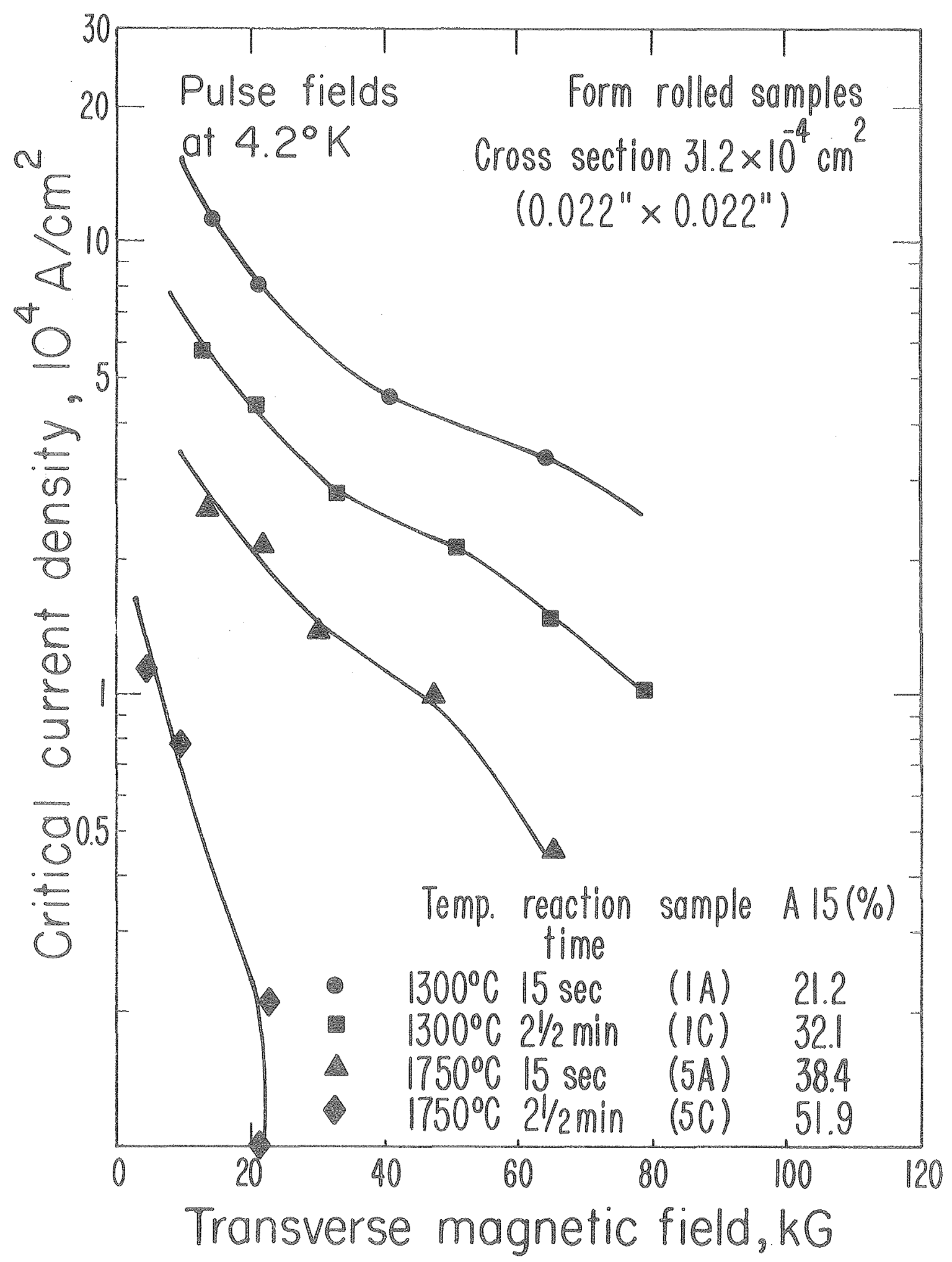

XBL 7683365

Fig. 25 


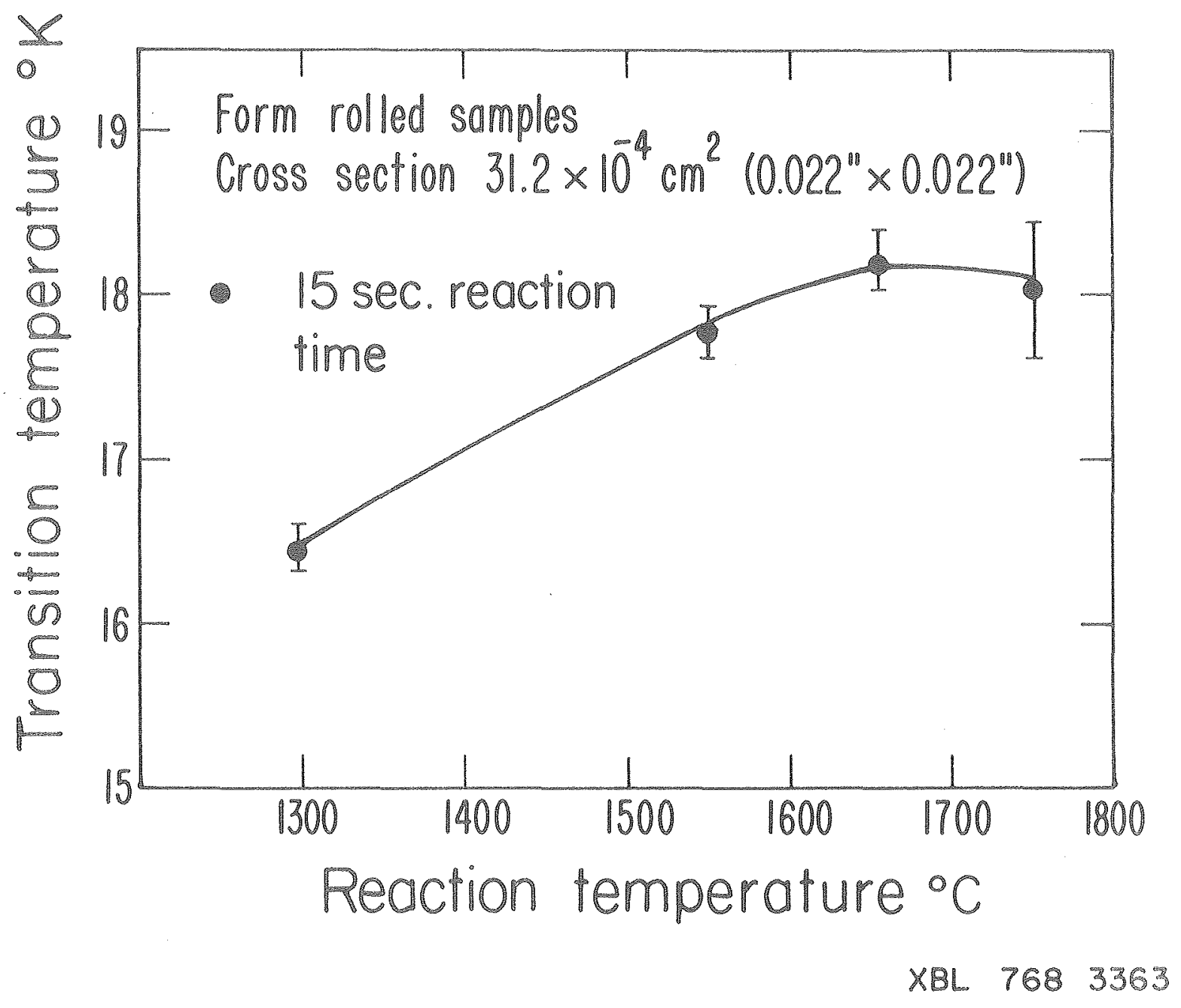

Fig. 26 
This report was done with support from the United States Energy Research and Development Administration. Any conclusions or opinions expressed in this report represent solely those of the author(s) and not necessarily those of The Regents of the University of California, the Lawrence Berkeley Laboratory or the United States Energy Research and Development Administration. 